\title{
Trends in lactose-derived bioactives: synthesis and purification
}

\author{
Carlos Vera $^{1}{ }^{1} \cdot$ Cecilia Guerrero $^{2} \cdot$ Andrés Illanes $^{2}$
}

Received: 5 October 2021 / Revised: 21 November 2021 / Accepted: 22 November 2021 / Published online: 21 January 2022

(c) Jiangnan University 2021

\begin{abstract}
Lactose obtained from cheese whey is a low value commodity despite its great potential as raw material for the production of bioactive compounds. Among them, prebiotics stand out as valuable ingredients to be added to food matrices to build up functional foods, which currently represent the most active sector within the food industry. Functional foods market has been growing steadily in the recent decades along with the increasing awareness of the World population about healthy nutrition, and this is having a strong impact on lactose-derived bioactives. Most of them are produced by enzyme biocatalysis because of molecular precision and environmental sustainability considerations. The current status and outlook of the production of lactose-derived bioactive compounds is presented with special emphasis on downstream operations which are critical because of the rather modest lactose conversion and product yields that are attainable. Even though some of these products have already an established market, there are still several challenges referring to the need of developing better catalysts and more cost-effective downstream operations for delivering high quality products at affordable prices. This technological push is expected to broaden the spectrum of lactose-derived bioactive compounds to be produced at industrial scale in the near future.
\end{abstract}

\section{Graphical abstract}

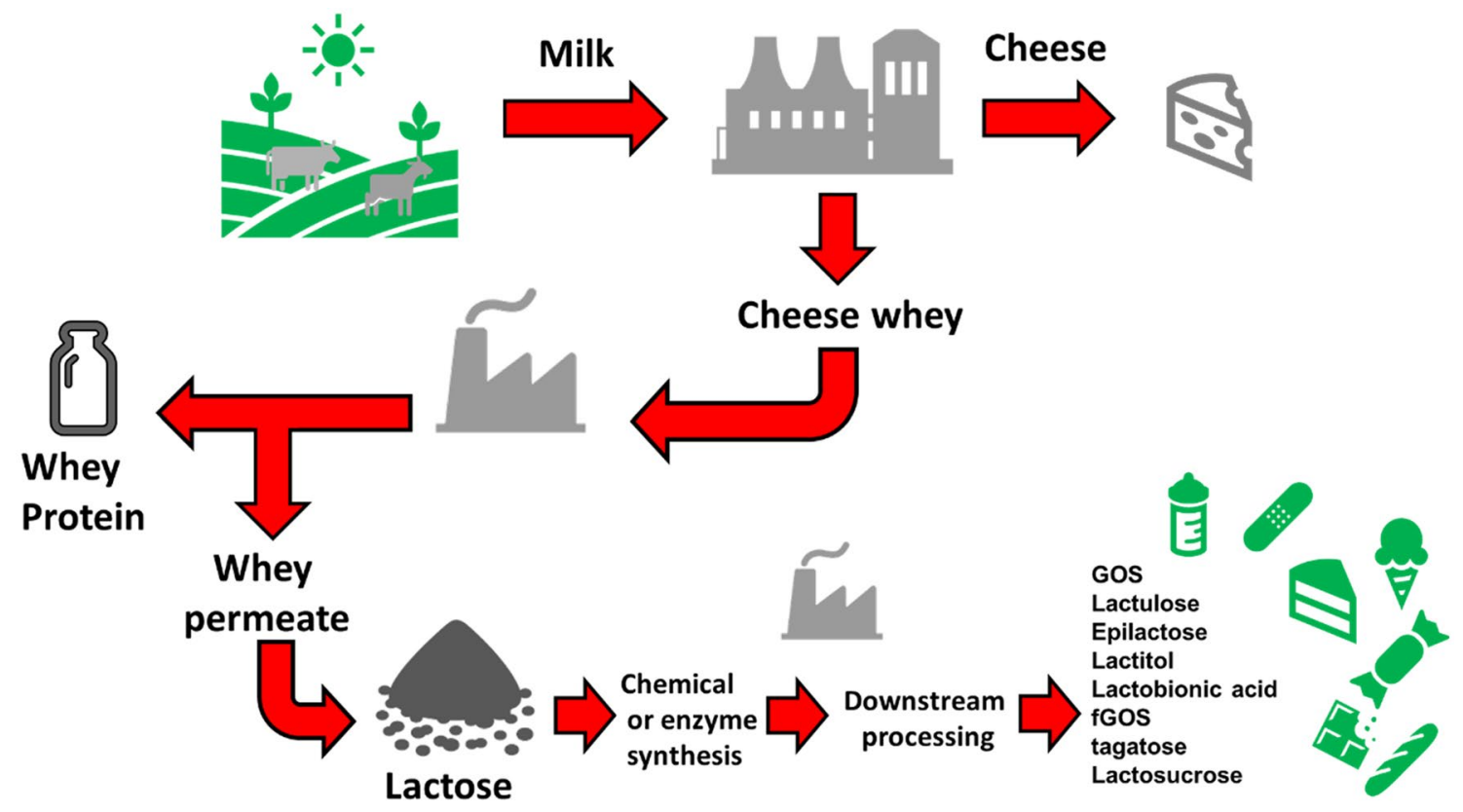

Keywords Prebiotic $\cdot$ Lactose $\cdot \beta$-Galactosidase $\cdot$ Oligosaccharide purification

Carlos Vera

carlos.vera.v@usach.cl

Extended author information available on the last page of the article 


\section{Introduction}

\section{Whey upgrading}

Whey (milk-whey or cheese-whey) is a major byproduct from cheese manufacturing. Formerly considered as a waste, nowadays the situation has evolved to a point in which whey is considered as a relevant co-product of cheese manufacturing, and a platform for the upgrading of whey and its components has been proposed as a way of turning it from a nuisance to an asset [1]. More recently, a holistic approach for cheese whey utilization has been envisaged within integrated biorefinery and circular economy concepts [2]. Whey is conveniently fractionated by membrane technology for recovering the whey proteins, which are now most valuable ingredients for the food industry [3]. After recovering whey proteins, whey permeate is produced, but with the increasing recovery of cheese whey proteins by ultrafiltration, surplus permeate is being produced with an estimated world production volume close to 100,000 tons of powder equivalent per year [4]. Lactose is the main component in cheese whey permeate, that can be converted into a palette of added-value products, mostly through bioprocesses involving whole cells [5] and enzymatic biotransformations [6]. Among the many options for whey lactose upgrading its use as substrate for the enzymatic production of oligosaccharides outstands [7].

\section{Lactose-derived prebiotics}

Functional foods are concisely defined as foods providing health benefits beyond basic nutrition [8]. Undoubtedly, consumers are increasingly aware of the connection between their eating habits and their health status [9]. Functional food production is considered the most dynamic sector within the food industry with an estimated world market over US $\$ 400$ billion, USA and Japan being the main producers, followed by some countries of the European Union [10]. Within the framework of functional foods, prebiotics are considered as important health-promoting bioactive compounds [11]. Several definitions of prebiotics have been proposed that have been evolved as more scientific information about their mode of action is being gathered. A currently accepted definition of prebiotic is: "a substrate that is selectively utilized by host microorganisms conferring a health benefit" [12]. However, the concept is continuously being revisited because of its scientific, technological, commercial and legal implications [13].

Prebiotics can act in other body sites than the gut, such as the skin or the vaginal tract [12]. However, their initial and main application refers to the beneficial stimulation of the gut microbiota. In this context, in order to be considered a prebiotic, a compound must be: resistant to degradation by acids and enzymes through the gastrointestinal passage, resistant to gastrointestinal absorption, fermentable by the gut microbiota, and selectively stimulate the growth and/or activity of the colonic bacteria associated with health and well-being, mainly Bifidobacteria and Lactobacilli. It must also withstand the harsh processing conditions of the food matrix that contains it, like high temperature, low $\mathrm{pH}$ and Maillard reaction conditions [14]. Selective fermentation in the large intestine is the most stringent criteria and usually the most difficult to meet [15]. Fermentability by the intestinal microbiota can be assessed both by in vitro and in vivo tests [16]. In principle, in vivo tests should have a better predictability; however, the use of in vitro simulations of human digestion has become widespread, being less labor intensive, cheaper, faster and free from ethical restrictions [17]. Dynamic digestion model reactors have been proposed to mimic the gastrointestinal functioning [18]. Description of a dynamic gastrointestinal simulator can be found in http://www.cial.uam-csic.es/simgi/. This type of simulators in being increasingly used for assessing the prebiotic potential [19, 20].

Prebiotics market has experienced a significant expansion along with the current trend of healthier eating habits. The global market for prebiotics was estimated in US\$ 4.5 billion in 2020 and, despite the COVID-19 crisis, the market is estimated to expand to US $\$ 8$ billion by 2026 [21]. In fact, an upward surge for prebiotics is expected during COVID-19 crisis associated with the immune system stimulation that prebiotics confer.

Most prebiotics are non-digestible oligosaccharides (NDOs), even though the concept is not restricted to them. Most important NDOs are the fructans: inulin and fructooligosaccharides (FOS), and galactans: galactooligosaccharides (GOS) [22, 23], all of them properly considered as prebiotics. Present FOS world market is estimated in US\$ 2.2 billion with an annual increase rate of $10 \%$ [24], while a inulin market of US\$ 1.4 billion was estimated for 2019 with an annual increase rate of $6.4 \%$ [25]. The present GOS World market is estimated close to US\$ 880 million with an annual increase rate of $8.3 \%$ [26].

Most prominent lactose-derived prebiotic is GOS; however, other lactose-derived bioactive compounds have been considered as prebiotics or prebiotic candidates [27]. Lactulose (4- $O-\beta$-D-galactopyranosyl-Dfructose), even though being used mostly as a drug for the treatment of hepatic encephalopathy and chronic constipation, is properly considered a prebiotic [28]. Other lactose-derived bioactive compounds that are considered as health-promoting agents are: lactosucrose 
( $O$ - $\beta$-D-galactopyranosyl-(1-4)- $O$ - $\alpha$-D-glucopyranosyl(1-2)- $\beta$-D-fructofuranoside) [29], lactitol (4-O- $\beta$-Dgalactopyranosyl-D-sorbitol) [30], lactobionic acid (4-O- $\beta$-galactopyranosil-D-gluconate) [31], tagatose (3S,4S,5R)-1,3,4,5,6-pentahydroxy-hexan-2-one) [32] and fructosyl-galacto-oligosaccharides (fGOS) [33].

\section{Synthesis of lactose-derived prebiotics}

\section{Galacto-oligosaccharides}

Galacto-oligosaccharides (GOS) are NDOs composed by a variable number of galactosyl units, and one terminal glucose unit linked by different types of glycosidic bonds. The prebiotic condition of GOS has unambiguously proven. GOS mimic the bifidogenic effect of human milk oligosaccharides (HMOs) by stimulating a healthy intestinal microbiota and the development of the immune system in newborns [34]; they also improve the intestinal motility, promote vitamin synthesis, increase calcium absorption, reduce the levels of blood cholesterol and triglycerides and the risk of colon cancer development [35]. Chemical synthesis of GOS is an exceedingly complex task since each aldohexose has one primary and four secondary hydroxyl groups so that the number of possible chemical structures is extremely high [36]. Therefore, GOS are produced exclusively by the $\beta$-galactosidase catalyzed reaction of lactose transgalactosylation, taking advantage of the selectivity and specificity that are inherent to enzymes. This is a kinetically-controlled reaction, in which lactose acts both as donor and acceptor of the galactosyl moiety, where lactose transgalactosylation and hydrolysis compete (see Fig. 1). Therefore, low water activity is required to depress the hydrolytic potential of the enzyme, which is obtained by working at (very) high lactose concentrations and moderately high temperatures [37]. Despite being a well-established industrial process, there are still several challenges related to their production that are mostly referred to the optimization of the enzymatic transgalactosylation reaction and the improvement in downstream operations, since GOS yields obtained with the enzymes in use rarely exceed $40 \%$, so that biocatalyst optimization is still a major field of research [23, 38].

\section{Lactulose}

Lactulose is a synthetic non-digestible disaccharide that is mainly used as a drug, but it is properly a prebiotic and being used as such, especially in oriental countries [39]. At present, most lactulose is produced by chemical synthesis by means of the Lobry de Bruyn-Alberda van Ekenstein arrangement, where the glucose residue in lactose is isomerized into fructose. Environmental concern and pressure for complying with the green chemistry principles have prompted active research on its enzymatic production [40]. A sound comparison between these two alternatives was presented by Sitanggang et al. [41]. There are two enzymatic routes for lactulose synthesis. The first one is the transgalactosylation of fructose with lactose catalyzed by $\beta$-galactosidase. This route has been thoroughly studied, having the advantage of using robust and inexpensive commercial enzyme preparations [42], but the disadvantage of using a second substrate (fructose) usually in significant excess [43]. This is a kinetically-controlled reaction and inevitably a mixture of lactulose and GOS will be produced since lactose will compete with fructose for being transgalactosylated by the enzyme. This will make this strategy inadequate for producing lactulose for medical use [44], but might be a good strategy for producing it for food use since both GOS and lactulose are prebiotics that may act synergistically [45]. A second enzyme route has been proposed which is based on the ability of the promiscuous enzyme cellobiose 2-epimerase to catalyze the direct isomerization of lactose into lactulose. This strategy has the obvious advantage of not requiring a second substrate, but several issues remain to be solved before making it a viable alternative for industrial lactulose production. The most promising enzyme is the one from Caldicellulosiruptor saccharolyticus, which is produced as a recombinant protein in an Escherichia coli host. Acting on lactose, the enzyme will catalyze both its isomerization and epimerization yielding a mixture of lactulose and epilactose
Fig. 1 Enzymatic synthesis of GOS. A Simplified scheme of reaction mechanism. B Products concentration during enzymatic synthesis
A

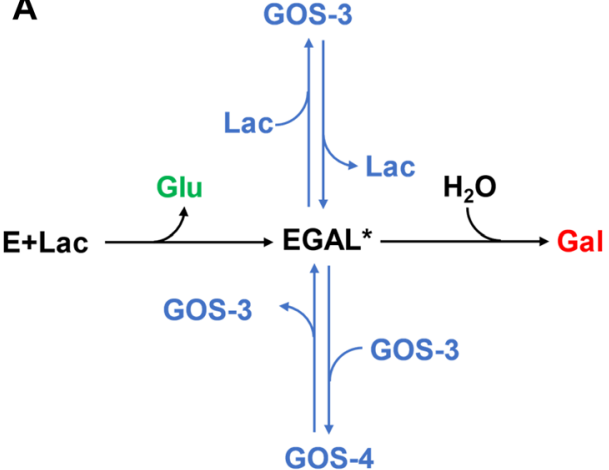

B

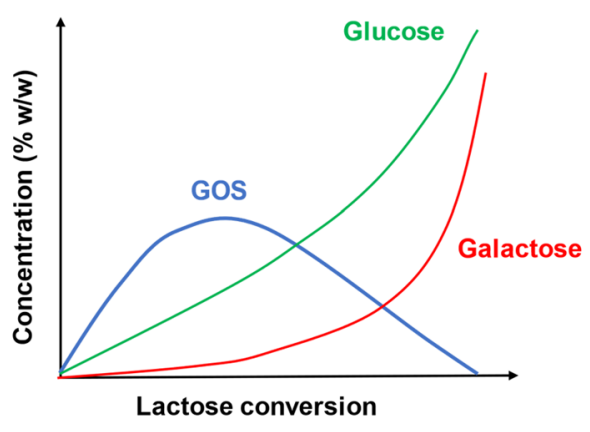


[46], so the enzyme has been engineered for increasing its activity and selectivity $[47,48]$. The enzyme is not available commercially and its production in a GRAS host is a prerequisite for its use in the food and pharmaceutical industries, but the forecast is that it will turn into the technology for lactulose industrial production in the forthcoming years [49].

\section{Other lactose-derived health promoting bioactive compounds}

Even though not properly considered as prebiotics, several lactose-derived compounds are considered as health promoting agents.

Epilactose: is a $\mathrm{C} 2$ epimer of lactose (4-O- $\beta-\mathrm{D}-$ galactopyranosyl-D-mannose), which is formed through a 2,3 enediol rearrangement of lactose (Lobry de Bruyn-Alberda van Ekenstein transformation). Epilactose was detected for the first time, in small concentrations, in thermally treated milk [50]. It is also found in low amounts in lactulose preparations obtained by alkaline isomerization of lactose. Despite studies have shown that epilactose is a potential prebiotic compound [51], the complexity of its synthesis and the very low reaction yield attained, discouraged the early epilactose development. However, the recent discovery of cellobiose 2-epimerase offers an attractive route for epilactose synthesis [52], so it is expected a boost on this field in the next years. For instance, Krewinkel et al.[53] reported that cellobiose 2-epimerase from the mesophiles Flavobacterium johnsoniae and Pedobacter heparinus are able to catalyze the synthesis of epilactose with a reaction yield around $33 \%$, without formation of side product. More recently, Chen et al. [54] produced epilactose from cheese whey $(300 \mathrm{~g} / \mathrm{L})$ using the cellobiose 2-epimerase from Thermoanaerobacterium saccharolyticum expressed in Bacillus subtilis. Then, they hydrolyzed the remaining lactose with the $\beta$-galactosidase form Bifidobacterium bifidum and removed the monosaccharides using selective fermentation with Saccharomyces cerevisiae. Finally, the GOS, and the residual monosaccharides were separated using cation exchange chromatography; obtaining epilactose with a purity higher than $98 \%$ and a $24 \%$ yield.

Lactosucrose: is a mildly sweet synthetic trisaccharide composed of galactose, glucose, and fructose. It can be produced by transfructosylation of lactose with sucrose using $\beta$-fructofuranosidases, or by transgalactosylation of sucrose with lactose using $\beta$-galactosidases. Both are kinetically controlled reactions, where transglycosylation and hydrolysis reactions compete. It is considered a potential prebiotic and it is used as a health promoting compound in several functional foods in Japan, where it is labeled as FOSHU (food for specific health use) [55]. Enzymes are customary used in free form, but immobilization has been proposed as a way of reducing the impact of catalyst cost on production cost [56].
Lactitol: is a non-natural sugar alcohol produced from lactose by hydrogenation with metal catalysts. It shares some of the properties of NDOs and as such has been used within the food sector as a low-calorie sweetener and also as a mild laxative, and has been proposed as adequate for consumption by diabetic patients. In the medical field, it has been used in the treatment of hepatic encephalopathy as an alternative to lactulose; also several non-food applications have been claimed for lactitol [30, 57].

Lactobionic acid: is a lactose-derived polyhydroxy acid [31]. Lactobionic acid is chemically produced by oxidation of the aldehyde group of the glucose moiety of lactose in an energy intensive process [58], so that the enzymatic synthesis with $\mathrm{NADP}^{+}$-dependent glucose-fructose oxidoreductase [59], the cellobiose dehydrogenase/3-HAA-laccase system [60] and the whole cell biosynthesis with Pseudomonas taetrolens [61] have been proposed as more ecofriendly alternatives. Lactobionic acid has several applications in the biomedical field (drug delivery, tissue engineering, organ transplantation) in cosmetics (anti-aging and regenerative skin products), in the chemical industry (surfactant and cobuilder in biodegradable detergents), and in the food sector as a food additive in several products as antioxidant, stabilizer, acidifier, antistaling, mineral absorption enhancer and gelling agent [58]. Beyond this, lactobionic acid share some of the properties of prebiotics by promoting a healthy gut microbiota. Recently, lactobionic acid has emerged as a key molecule for developing nanoparticle platforms and biomaterials for therapeutic applications [62].

Tagatose: is a galactose isomer and a fructose epimer; it is considered a rare sugar because it is scarcely found in nature. Being produced from galactose, it can be considered a lactose-derived substance in the sense that galactose will come from lactose hydrolysis. Originally produced by chemical synthesis [63], nowadays it is produced by biocatalysis because of environmental and technical reasons [64]. Biological production of tagatose was initially based on the oxidation of dulcitol (galactitol) by Arthrobacter globiformis [65]. Later on, the bioconversion of psicose to tagatose (and talitol) [66] and the oxidation of galactitol with galactitol 2-dehydrogenase [67] were evaluated. However, these routes proved be technologically inviable because the enzyme is $\mathrm{NAD}^{+}$-dependent and the substrates are costly. A major breakthrough was the discovery that the enzyme arabinose isomerase (EC 5.3.1.4) that catalyzes the reversible isomerization of arabinose into ribulose could also catalyze the isomerization of galactose into tagatose, although with a lower affinity and reactivity for galactose than for arabinose [68]. Therefore, considerable effort has been made in the last decade to engineer this enzyme for tagatose production [69], including genetic engineering [70], protein engineering [71] and biocatalyst engineering strategies [72], both with 
isolated arabinose isomerase [72] and whole-cells containing it [73]. The industrial production of tagatose considers lactose hydrolysis, either chemically with mineral acids or enzymatically with $\beta$-galactosidase, followed by isomerization with arabinose isomerase [74]. The synthesis of tagatose has been performed with different immobilized arabinose isomerases [75]. A quite interesting trienzymatic system has been proposed for tagatose production from lactose, composed by Bacillus circulans $\beta$-galactosidase, Streptomyces rubiginosus glucose isomerase and Enterococcus faecium arabinose isomerase, immobilized separately in Eupergit to produce a mixture of tagatose and fructose [76]. Later on the same authors reported the onepot operation with the enzymes immobilized separately and coimmobilized in commercial Eupergit supports, the latter being more efficient [77]. The most important application of tagatose is as a hypocaloric and non-cariogenic substitute of sucrose in their multiple food uses [78]. Tagatose was awarded GRAS status in 2000 and it is being evaluated as a possible antidiabetic agent [79]. Beyond its use as a low-calorie sweetener, its excellent functional properties open up applications in multiple directions: as a health promoting agent in functional foods, in oral hygiene, as a drug for the treatment of obesity, anemia and hemophilia and as antioxidant in organ preservation [80].

More recently, several efforts have been done to develop a route for the production of tagatose from fructose [81], being the Korean company CJ CheilJedang Corp involved in the development such technology [82, 83]. Two alternative biocatalysts have been constructed by a protein engineering approach: one based on a class II 1,6-bisphosphate aldolase and the other based on the tagaturonate 3 -epimerase [81, 83].

Fructosyl-galacto-oligosaccharides ( $f G O S$ ), also called lactulose-derived oligosaccharides, are NDOs indirectly produced from lactose, since they are synthesized from lactulose in a way similar than the production of GOS from lactose. The reaction is catalyzed by $\beta$-galactosidase that accepts lactulose as donor and acceptor of the transgalactosylated galactose residue [84]. The difference with GOS is that fGOS have a terminal fructose instead of glucose unit, which is a subtle difference, so that it has been proposed that the prebiotic condition of GOS should be extended to fGOS [85]. fGOS have been synthesized with $\beta$-galactosidases from $K$. lactis [86], B. circulans and Aspergillus oryzae, the latter being by far the best in terms of fGOS productivity [33]. fGOS derive from lactulose, which is both a prebiotic and a drug, so that fGOS are likely to have functionalities in both directions. Actually, fGOS have revealed interesting prebiotic features producing a significant reduction in gut populations of proinflammatory bacteria and a significant increase in beneficial populations, such as Bifidobacteria, and also reduction of colorectal cancer in model animals [87].

\section{Manufacturing technologies for lactose-derived prebiotics}

Most of the large-scale manufacturing processes for lactose derivatives start from pure lactose as raw material, because it facilitates product purification. Purification may represent up to $50-60 \%$ of the producing cost [38], so the use of pure lactose instead of whey or whey permeate may reduce the cost of manufacture. Also, at some scales of operation, the cost of purchasing lactose is less than the cost of conditioning the whey or whey permeate [88]. However, there are some exceptions: for instance, Nestlé has proposed a process to produce GOS from demineralized whey permeate (see Fig. 2A). Therefore, it should be emphasized that the choice of raw material will always depend on a rigorous technoeconomic analysis. Indeed, the use of whey or whey permeate can be attractive from a circular economy perspective.

Independent on the raw material and the product, the upstream processing involves relatively simple operations, which are devoted to substrate conditioning, e.g., dissolution, addition of metal cofactors, lactose hydrolysis if corresponding, $\mathrm{pH}$ and temperature regulation (see Fig. 2). Afterward, the properly conditioned substrate is chemically transformed. If the conversion of the substrate does not require a regio- or stereoselective catalysis, such as in the case of lactobionic acid and lactitol, chemical route is preferred [89]. Conversely, biocatalysis has a prominent role when regio- or stereoselectivity are mandatory. For instance, the ability of GOS to resist the hydrolysis by the intestinal enzymes is due to the $\beta$-glycosidic linkage between the monosaccharide units [27]. Chemical synthesis of oligosaccharides having $\beta$-glycosidic linkages is quite challenging and laborious [90]. Furthermore, the regioselectivity of the chemical synthesis is hard to control since each monosaccharide unit has several hydroxyl-groups available [91]. Hence, GOS are synthetized using $\beta$-galactosidases as these enzymes catalyze transgalactosylation reaction retaining the $\beta$-glycosidic configuration of the galactose moiety in lactose [27].

During the past three decades, huge advances were reached on the synthesis and upstream operations in the manufacturing of bioactive carbohydrates, being the downstream operations currently the more challenging [38]. On a large scale, the purification of lactose-derived prebiotics is similar to sugar refining processes, being the major stages: fractionation, discoloration, demineralization, protein and microorganisms removal, and concentration and/or spray drying [23, 88]. Among all the steps comprising the downstream processing of GOS, research has been mainly focused on carbohydrate fractionation [38,92], because it is the most expensive and technologically challenging unit operation [38]. Undesired carbohydrates, typically glucose, galactose and the unreacted lactose, are partially removed as they add 
Fig. 2 Manufacturing process for lactose-derived prebiotics. a GOS production by Nestle, adapted from GRAS notice 620 [104]. b GOS production by Yakult Pharmaceutical Industry Co., Ltd., adapted from GRAS notice 334 [102]. c Tagatose production proposed by $\mathrm{CJ}$ Cheiljedang, adapted from GRAS notice 352 [136]

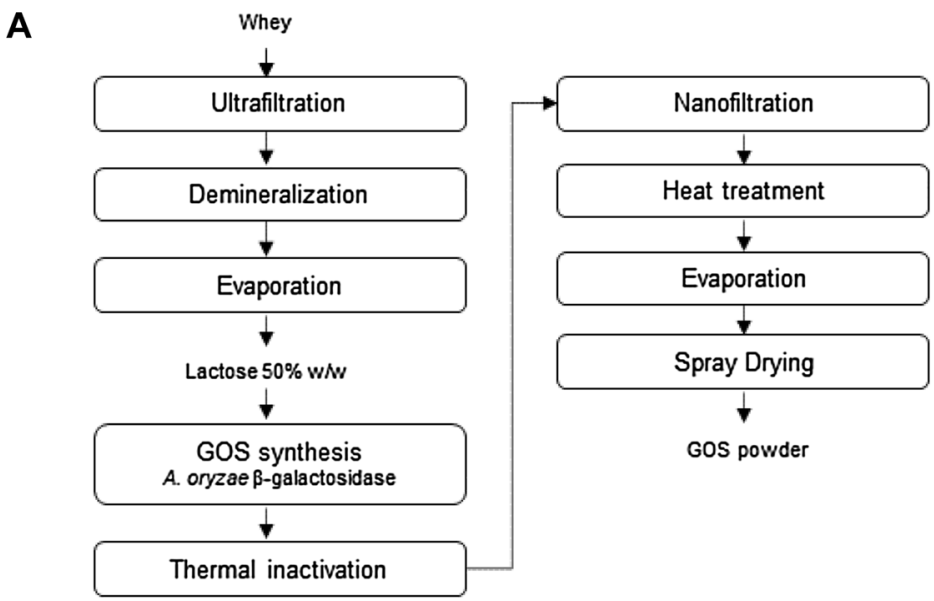

B
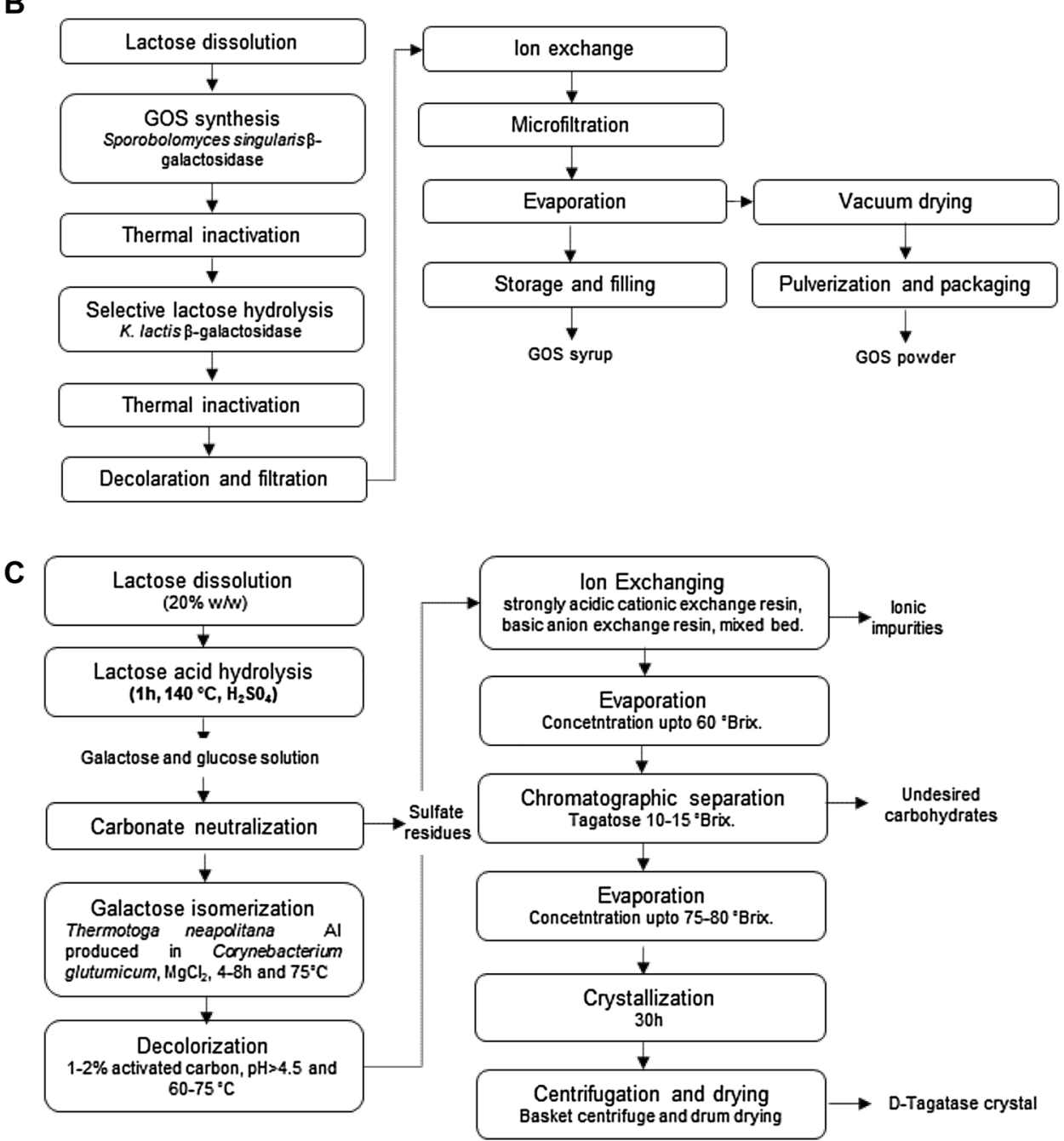

sweetness, increase the calorie content of the product, are cariogenic and non-prebiotic $[38,92]$. However, to keep the manufacturing cost at an acceptable level, the content of unwanted carbohydrates is typically around $40 \%$ of the total carbohydrates in the final product [38].

\section{Downstream processing of lactose-derived prebiotics}

The design of the downstream processing requires the record (or determination) of the physicochemical properties of the 
product of interest and the main impurities present in the product stream, the determination of the operational stability of the product, the knowledge of the available technologies and the corresponding sanitary regulations, the determination of the critical control points and the validation of the process [93]. Having all this information, the engineers should tackle the design of the purification operations to reach the final product specifications and accomplish the legal regulations, minimizing the cost associated to downstream processing. The design of downstream operations is complex and the experience of the designer is critical. The simplest way to go about is to adapt a similar process that has already proven successful. A more elaborated strategy is based on the heuristic rules to guide the selection of the unit operations required and their sequence with the purpose of reducing downstream costs. A third strategy, even more complex and time consuming, consists in a rigorous analysis of the purification strategy based on the experimentation, modeling, simulation and computational optimization [93, 94]. Since downstream processing is currently the most challenging stage in the manufacture of lactose-derived prebiotics, the main advances on carbohydrate fractioning technologies will be reviewed in detail in the following sections. Conventional downstream operations, whose design, and operation is well stablished, e.g., evaporation, heat exchange, demineralization, decolorization and centrifugation, will not be considered in this review. The main technologies used for lactose-derived prebiotics purification are presented in Fig. 3. These include membrane separation, chromatography, adsorption, solvent precipitation, microbial selective fermentation and enzyme-assisted purification. All these technologies are thoroughly reviewed in the next sections, providing examples of their application in the purification of lactose-derived prebiotics.

\section{Membrane separations processes}

Membrane separation processes (MSP) have been key unit operations in the food industry since the 1960's, allowing concentration and fractionation in a single operation conducted in aqueous media without altering the physicochemical properties of the components of the system [95, 96]. In simple terms, MSP consist in passing under pressure a feed stream containing a mixture of compounds through a semipermeable membrane, obtaining a stream enriched in the rejected compounds (retentate) and a stream enriched in those compounds passing through the membrane (permeate) [93-95]. MSP can operate on a dead-end mode where the feed stream is forced at high pressure against the membrane, or in cross-flow mode where the feed stream runs
Fig. 3 Common downstream technologies used for lactosederived prebiotics fractionation

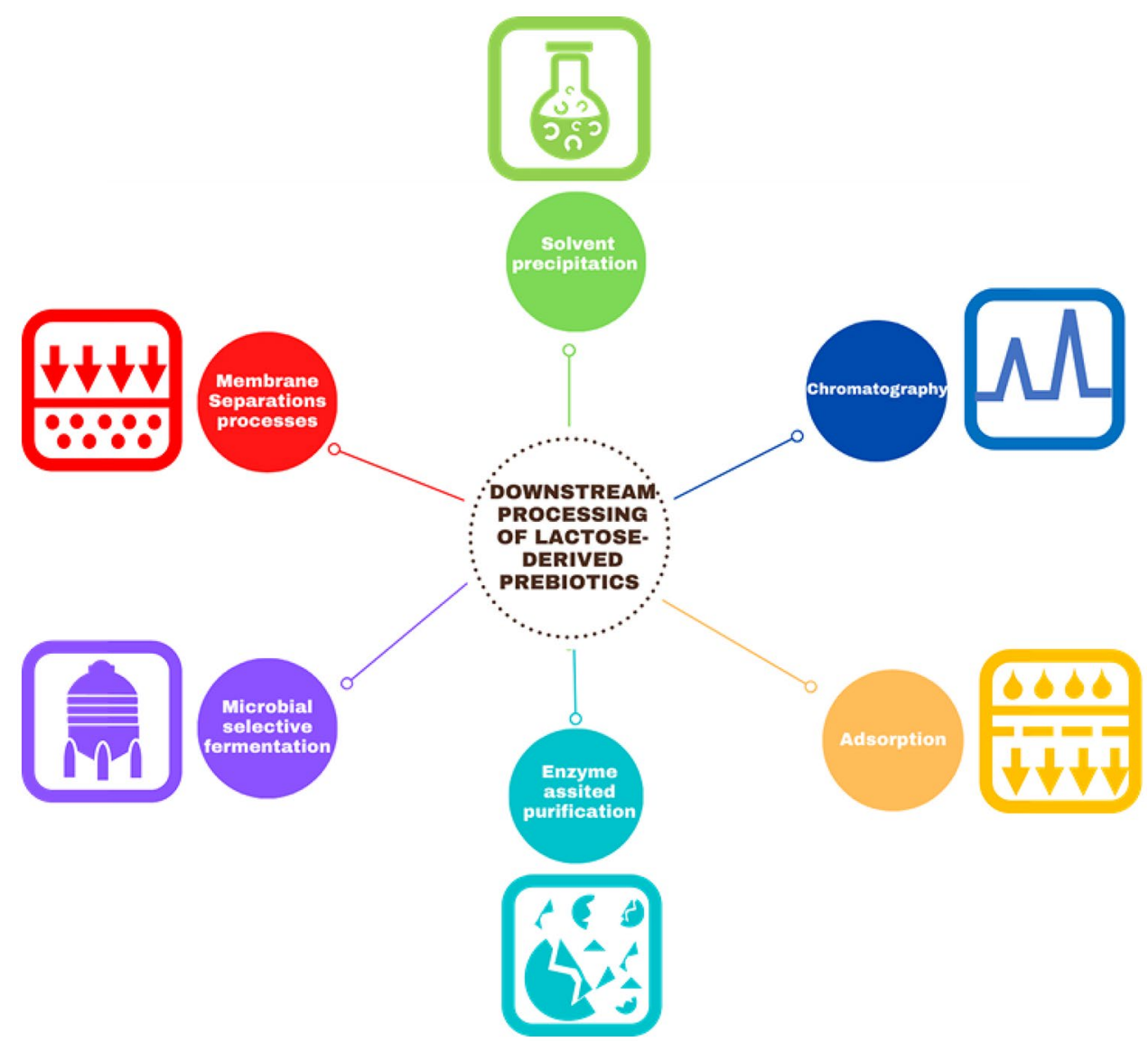


parallel to the membrane and solutes go through it thanks to the pressure difference on both sides of the membrane, the latter being the most used mode of operation [95]. The performance of fractionation by MSP is expressed in terms of the permeate flux and selectivity of the membrane, and strongly depends on concentration polarization and fouling of the membrane. Concentration polarization can be reversed by changing the operating conditions, while membrane fouling tends to be irreversible so that membrane cleaning is a crucial operation [97]. MSP has several standout features: it allows continuous operation, no additional water is required to the system, it can be easily scaled up and hybrid operations can be configured [93, 96, 97]. On the other hand, MSP drawbacks are: reduced useful life, low selectivity and flux, linear scale-up, membrane fouling and concentration polarization [98-100].

Depending on the pore size of the membrane, MSP are classified as microfiltration (pore sizes between 0.1 and $10 \mu \mathrm{m}$ ), ultrafiltration (pore sizes between 0.001 and $0.1 \mu \mathrm{m}$ ) and nanofiltration (pore sizes between 0.0001 and $0.001 \mu \mathrm{m}$ ) [95]. Microfiltration is mainly used for reducing the microbial count, for the fractionation and removal of particles in suspension (fat particles and cell debris) and also as a pretreatment operation for ultrafiltration. The pressure gradient used as driving force in microfiltration ranges from 10 to $200 \mathrm{kPa}$ [96]. Owing to the cutoff value of most microfiltration membranes, solutes, such as proteins and carbohydrates, may permeate and require other operations for their removal. For example, Neo Cremar Co. Ltd. (Korea) reported that in the production of Nature's GOS-L the reacted medium is filtered in several steps through a diatomite filter aid and a cartridge filter with a pore size of $0.5 \mu \mathrm{m}$, and then microfiltered in membranes having pore sizes between 0.22 and $0.25 \mu \mathrm{m}$ prior to evaporation [101]. Likewise, Yakult Pharmaceutical Industry Co., Ltd. reported a microfiltration step to further remove microparticles and microorganisms prior to concentration by evaporation, in the production of Oligomate 55 N/55NP GOS, as shown in Fig. 2b [102]. Also, the use of microfiltration is amply reported as pretreatment to reduce the microbial count in cheese whey and also for bleaching, concentration and separation of macronutrients [91].

Ultrafiltration is mostly used for the removal of macromolecules in the range from 5000 to $100,000 \mathrm{Da}$ applying transmembrane pressures between 100 and $500 \mathrm{kPa}$, using ceramic and polymeric membranes [96-103]. It is a common operation in the dairy industry for the separation of colloids and macromolecules, mostly proteins. In fact, ultrafiltration is used for the recovery of proteins from whey (casein micelles and serum proteins), which is a valuable asset in the cheese manufacturing industry [95]. Ultrafiltration is the most suited operation in whey fractionation since it is highly specific for protein removal and mild, not altering the properties of the compounds. Nestle Nutrition reported the use of ultrafiltration for producing whey permeate as a lactose source used as substrate for the enzymatic synthesis of Nestle GOS [104]. Likewise, Clasado Inc. reported the use of ultrafiltration devices with spiral wound $10 \mathrm{KDa}$ membranes for the removal of $\beta$-galactosidase and other remnant proteins and peptides from the spent medium after GOS synthesis in the production of Bimuno GOS [105].

All compounds involved in GOS synthesis, oligosaccharides and sugars, are in the 180-1600 Da range [107], so microfiltration and ultrafiltration are no options for GOS purification. However, nanofiltration allows fractionating compounds in the above range [95] being in principle applicable for GOS synthesis. Commercial GOS preparations mainly contain di-, tri-, tetra-, penta- and hexa-saccharides [101, 102, 104-106], and presumably trisaccharides (molecular weight $342 \mathrm{Da}$ ) and tetrasaccharides (molecular weight $504 \mathrm{Da}$ ) are those more relevant in terms of prebiotic effect [108]. Therefore, the difference in molecular mass with the undesired carbohydrates (lactose and the monosaccharides) is rather small, so only a partial purification of GOS is attainable by nanofiltration. In this context, Goulas et al.[109] were the first to report the use of nanofiltration in cross-flow mode for GOS purification; they compare several membranes with respect to their performances and selected DS-51-HL operating at $60{ }^{\circ} \mathrm{C}$ and 13.8 bar of transmembrane pressure. This configuration allows them to retain 98 , 89 and $18 \%$ of the GOS, lactose and glucose in the feed stream, respectively. Michelon et al. [110] obtained a GOS purification yield of $61 \%(\mathrm{w} / \mathrm{w})$ using a dead-end cell nanofiltration unit operating with a NP30 polyethersulphone membrane at $35^{\circ} \mathrm{C}$ and $3 \mathrm{MPa}$ of transmembrane pressure, suggesting nanofiltration as an intermediate stage of purification. Ren et al. [111] reported the use of a continuous ultrafiltration membrane reactor coupled to a nanofiltration step for GOS purification. Ultrafiltration was conducted with a $50 \mathrm{kDa}$ nominal molecular weight cutoff (NMWCO) UOF4 membrane operating at $3 \mathrm{bar}$ and $50^{\circ} \mathrm{C}$, while nanofiltration was conducted at 10 bar and $50{ }^{\circ} \mathrm{C}$ using a DL1812C-34D membrane with a NMWCO of 400-600 Da. This configuration proved to be capable of continuously producing $80 \%$ (w/w) pure GOS, which is a higher GOS content than in regular commercial GOS preparations [101, 102, 104-106]. In order to reduce the microbial fouling, Pruksasri et al.[112] evaluated the nanofiltration of GOS using a stirred deadend cell at 5 and $60{ }^{\circ} \mathrm{C}$. Best result were obtained with a NPO30 membrane working at 45 bar and $5{ }^{\circ} \mathrm{C}$, obtaining a GOS purity of $85 \%$. Córdova et al. [100] using a stirred dead-end cell evaluated the effect of the solute concentration in the feed stream on the performance of a nanofiltration unit. These authors tested solutes concentrations from 20 to $40^{\circ} \mathrm{Brix}$ and transmembrane pressures from 5 to $40 \mathrm{bar}$. Membrane NPO10 delivered the highest flux at all operational conditions tested, with total GOS retention in highly 
concentrated solutions $\left(40^{\circ} \mathrm{Brix}\right)$ at 40 bar. The merit of these results is that they show that nanofiltration can fractionate highly concentrated crude GOS solutions without a prior purification step despite of the adverse effect of concentration polarization. Also, the authors evaluated a purification process consisting in three-stage serial nanofiltration units operating at critical transmembrane pressure (TMPc) and high solute concentration in the feed stream, obtaining a product stream with $55 \%(\mathrm{w} / \mathrm{w})$ GOS, which is similar to the average composition of commercial GOS preparations [101, 102, 104-106]. Aguirre Montesdeoca et al. [98], evaluated the purification of GOS in continuous mode using a cascade nanofiltration membrane system and show the inverse relationship between purity and recovery and how can it be handled by an appropriate MSP design. In this line, only a moderate increase in GOS purity, from 40.4 to $46.7 \%$, was achieved when constraining the recovery to values higher than $90 \%$. At industrial level, Nestle Nutrition reported the use of nanofiltration for the purification of GOS, not only for reducing the content of unreacted lactose and monosaccharides in the raw GOS, but also for increasing the efficiency of spray drying and reducing the mineral content [104]. Likewise, Clasado Inc. reported the use of nanofiltration with similar purposes for the production of spray-dried powder of Bimuno, a highly pure commercial GOS product [106].

\section{Chromatography}

This is a high-resolution operation where a mixture of compounds is separated according to their partition in two phases, one of them being stationary (sorbent) and the other mobile. If the mobile phase is a liquid, the operation is called liquid chromatography, being this the most used method for the large-scale fractionation of carbohydrates [113-115]. With respect to other classes of compounds that present differences in their functional groups, carbohydrates are highly difficult to fractionate, since they mainly differ in the spatial orientation of their atoms [116]. Because natural (nonderivatized) carbohydrates are highly polar, hydrophilic interaction liquid chromatography (HILIC) and normal phase chromatography might seem as first options for their resolution [116]. HILIC uses a stationary phase functionalized with a polar group, e.g., amino, cyano, phenyl, amino-alkyl, diol, and a mobile phase containing a water miscible solvent, like methanol or acetonitrile, so elution time increases as the polarity of the compound increases [117]. On the other hand, normal phase chromatography employs a highly polar stationary phase and a less polar mobile phase, so less polar analytes are eluted first [118]. The latter techniques are not attractive for large scale operation since the mobile phase typically includes an organic cosolvent. Thus, the preferred option is ligand-exchange chromatography, which uses a cation-exchange resin saturated with a metal ion (e.g., of a transition metal) as the stationary phase and water as mobile phase [119]. Usually, hot water is required to improve resolution and increase the peak bandwidths [120]. Also, an acid at a low concentration $(0.1-1 \mathrm{mM})$ is generally added to the mobile phase to prevent the accumulation of proteins onto the sorbent. Nevertheless, the use of an acid promotes the counter-ion stripping, making necessary the cleaning and regeneration of the sorbent [120]. Ligand-exchange chromatography allows the efficient fractionation of mono and oligosaccharides, polyols and simple organic acids [113-115]. The counter-ions control the separation performance, being $\mathrm{H}^{+}, \mathrm{Na}^{+}, \mathrm{K}^{+}, \mathrm{Ag}^{+}, \mathrm{Li}^{+}, \mathrm{Ba}^{2+}, \mathrm{Ca}^{2+}, \mathrm{Sr}^{2+}, \mathrm{Pb}^{2+}, \mathrm{Y}^{3+}, \mathrm{La}^{3+}$ and $\mathrm{Pr}^{3+}$ the most used [121]; however, some of them are excluded from food and pharmaceuticals applications for being toxic [120]. Despite that the sorbent is a cation exchanger, the separation mainly obeys to a size-exclusion mechanism, so that the carbohydrates eluting first are the ones of higher molecular mass [121]; therefore, separation of carbohydrates with the same molecular mass, especially mono and disaccharides, is considerably more complex. Hydroxyl groups in carbohydrates form complexes with metal ions, leading to several weak interactions that control the sorbent selectivity, e.g., electrostatic forces, hydrophobic interactions, steric hindrance and van der Waals forces, among others [120, 121]. In addition, cation-ligated zeolites $[122,123]$ and activated carbon [124] have been used as sorbent in liquid chromatography of carbohydrates, because both materials have shown to be more cost effective than ligand-exchange resins [38]. Particularly, zeolites have attractive features as they use water as mobile phase, and the pore size and hydrophobicity/hydrophilicity of the particles can be easily modulated in order to improve the selectivity [123]. For its part, activated carbon stands out because it is cheap and easy to regenerate [38]; nevertheless, activated carbon columns generally use water/ethanol as mobile phase and gradient elution [124, 125].

Chromatography has been conventionally conducted in batch mode (elution mode). Here, small pulses of the mixture to be fractionated are introduced in the mobile phase, which is fed at the top of the packed column. The mixture elutes through the column along with the mobile phase, whilst the individual components of the mixture are separated according to the intensity of their interaction with the sorbent [126, 127]. Batch operation has the disadvantages of poor productivity (low throughput capacity), high eluent consumption and dilution of the purified compounds [126]. In order to solve those constraints, simulated moving bed (SMB) chromatography was developed during the last third of the past century $[127,128]$. SMB is a practical implementation of a continuous and counter-current chromatographic process. Consequently, SMB operation is more efficient and productive than batch mode. Furthermore, SMB operation allows obtaining pure products 
without the complete resolution of the compounds, a part of the mobile phase may be recycled, the operation is easy to scale-up and product dilution is reduced [38, 127, 128]. On the other hand, SMB operation has the disadvantages of higher equipment cost and more complex operation. Thus, it uses is only economically attractive for large-scale processes [38]. Design, modelling and validation of chromatographic separation of GOS in batch mode and SMB has been reported in detail [113-115, 128]. For instance, Wisniewski et al. [114] and Müeller et al. [115] evaluated at laboratory scale a SMB chromatography module for GOS purification, achieving a purity of over $99 \%$. Dendene et al. [129] studied the separation of lactose, lactulose and galactose by using cationic ion-exchange resins, observing that the adsorption isotherms of the studied carbohydrates were not independent, making the process modeling complex. On the same line, Kozempel et al. [130] reported a pilot process for the production of lactulose, obtaining a fair separation by using a $\mathrm{Ca}^{2+}$-exchange resin. However, the authors reported the need of an additional chromatographic step to remove the boric acid. More recently, Tamura et al. [131] evaluated a number of cation-exchange resins for the separation of galactose, tagatose and talose, obtaining the best result with $\mathrm{Na}^{+}$and $\mathrm{K}^{+}$as counterions and cross-linking of $6 \%$. In addition, the purification of lactobionic acid has been studied using cation-exchange resins [132]. In contrast to carbohydrates that present a linear adsorption isotherm, lactobionic acid has an unfavorable anti-Langmuir isotherm [132], which may lead to an asymmetrical (fronting) peak. Simulated moving bed reactor (SMBR) consists in a SMB chromatography apparatus in which a reaction occurs, being its use particularly appealing for reversible reactions since it allows the continuous removal of the product, so that reaction performance is improved [133]. This reactor configuration has been used for the synthesis of lactosucrose, leading to a slight increase in reaction yield [133]. To do so, the authors modeled and estimated the parameters of the SMBR for a $\mathrm{Na}^{+}$-exchange resin (Amberlite) as sorbent $[133,134]$.

The inspection of the GRAS notices for GOS at the website of the U.S. Food and Drug Administration (FDA), reveals that from a total of nine GOS preparation only GTC Nutrition explicitly informed the use of chromatography for the removal of unwanted carbohydrates, reaching a GOS purity of $90 \%$ for its discontinued product Purimine GO-P90[135]. In addition, CJ Cheiljedang, Inc informed the use of ion-exchange chromatography for the removal of glucose and galactose during the manufacturing of D-tagatose [136]. There, chromatography was conducted using a decolorized and concentrated syrup $\left(60^{\circ} \mathrm{Brix}\right)$ as feed stream, resulting in an almost pure (98\% D-tagatose) and diluted $\left(10^{\circ}\right.$ Brix $)$ stream.

\section{Adsorption}

Adsorption is a process in which one or more compounds (adsorbates) are transferred from a liquid or gas phase into a solid phase (sorbent) [137, 138]. Usually, adsorption is a four-stage operation: (i) the solutes are contacted with the sorbent, (ii) the sorbent is washed to remove the unabsorbed compounds, (iii) the adsorbates are desorbed using a proper eluent, and (iv) the sorbent is washed and regenerated [139]. Thus, adsorption operation only differs from adsorption chromatography in the manner of conducting the operation [140]. Adsorption occurs onto the surface of the solid phase because of the presence of unbalanced forces, resulting in the attraction of the adsorbates. In the case of physical adsorption, those are van der Waals forces, while chemical adsorption implies the formation and breakdown of chemical bonds. Physical and chemical adsorption are not isolated processes and often occur simultaneously [138]. Activated carbon is one of the preferred choices as sorbent because of its very large surface area, high porosity and high hydrophobicity. Also, zeolites, scavengers, activated alumina, lignite coke and bentonite are commonly used sorbent materials [137, 138]. In the case of reversible adsorption, the process is generally described using an equilibrium constant, which easily leads to a Langmuir or Freundlich adsorption isotherm [140]. Nevertheless, there are more complex adsorption isotherm patterns [141].

Fractionation of GOS [142] and fGOS [125] has been successfully attained by adsorption onto activated charcoal and desorption in ethanolic solutions. The above cited reports show that the intensity of adsorption increases with the molecular weight of the oligosaccharides, a higher content of ethanol being required to desorb them [125, 142]. In addition, fGOS were desorbed more easily than GOS [125]. Also, activated charcoal adsorption is used as a standard procedure for the large scale polishing of lactitol [143] and tagatose[144]. Aside from the traditional use of adsorption for product purification, one interesting approach was reported by Boon et al. [145], who evaluated the use of an activated carbon column to reduce the content of monosaccharides during the synthesis of GOS, since it is well-known that monosaccharides inhibit the transgalactosylation activity of $\beta$-galactosidases [146] and reduce the reaction yield [147]. The use of this strategy produced an increase of 30\% in the reaction yield [145]. Also, the authors determined the Langmuir isotherms of the mono-, di- and trisaccharides and modeled the behavior of the adsorption column, obtaining good agreement with the experimental data.

\section{Solvent precipitation}

Selective precipitation of carbohydrates in the presence of an organic solvent (generally ethanol) is a simple methodology 
for the purification of oligosaccharides [38, 148]. However, this procedure has been poorly developed because of the requirement of a high amount of the organic solvent and the need to recover it when the procedure is conducted at industrial level. For instance, Sen et al. [149] observed that a minimum ethanol concentration of $85 \%(\mathrm{v} / \mathrm{v})$ was required to fractionate the reacted mixture of GOS synthesis (raw GOS) at temperatures between 10 and $40{ }^{\circ} \mathrm{C}$; in addition, they suggested that optimal operation conditions for selective precipitation are the result of a careful decision-making process. This is because the ratio of GOS to lactose in the precipitate increased at lower total carbohydrate concentrations, while the percentage of GOS recovery increased with the total carbohydrate concentration. Besides that temperature had a positive effect on the GOS to lactose ratio in the precipitate [149]. On the other hand, most of the physiochemical properties of lactose and lactulose are similar, so that their separation by the techniques mentioned in the previous sections is quite challenging. Nevertheless, their solubilities are much different in water [150] and even more so in the presence of ethanol [151]. Thus, selective precipitation of lactose with ethanol appears as a sound technique for lactulose purification. Zanganeh and Zabet [151] using selective precipitation in the presence of ethanol $(85 \% \mathrm{w} / \mathrm{w})$ reported $87 \%$ of lactose removal at $37^{\circ} \mathrm{C}$. In the same line, most of the physiochemical properties of tagatose and its raw material (galactose or fructose) are similar, but their solubilities in alcohols are quite different (galactose $<$ tagatose $<$ fructose) [152]. Lee et al. [153] studying the synthesis of tagatose from fructose at laboratory scale reported that fractionation using ethanol as a precipitating agent allowed obtaining a tagatose purity of $99.9 \%$.

\section{Microbial selective fermentation}

Selective fermentation has been proposed as a non-conventional alternative for carbohydrate purification [154-156]. This process is based on the sequential consumption of the unwanted mono- and disaccharides present in the reaction medium by microorganisms subjected to carbon catabolic repression (CCR). CCR mechanisms in bacteria and yeast imply complex regulatory circuits for the induction and repression of genes, presumably related to the hierarchical consumption of the so-called "poor" carbon sources [157-159]. Typically, the process is conducted in such a way as to promote the transformation of unwanted carbohydrates into ethanol and carbon dioxide, which are easier to remove from the medium [154-156]. Thus, selective fermentation stands out as a simple and low-cost method for attaining high purity prebiotic preparations $[38,88,160]$. However, high biomass concentration is generally required for the effective removal of the contaminant sugars, and the generation of metabolites, like ethanol, glycerol, higher alcohols and organic acid, might make necessary to include additional purification steps to properly remove them $[44,160]$.

This strategy was first reported in the literature by Onishi et al. [161, 162], for the production of GOS with a $\beta$-galactosidase from Sterigmatomyces elviae CBS8119. They noted that glucose released during the synthesis of GOS negatively affected the transgalactosylation activity, resulting in decreased GOS yield. So, they carried out the growth of the enzyme producing strain and the synthesis of GOS simultaneously. This strategy allows them to reach GOS yields around $60 \%(\mathrm{w} / \mathrm{w})$. Almost a decade after, this strategy was reassumed by fermenting with $S$. cerevisiae or Kluyveromyces lactis the raw GOS obtained using commercial $\beta$-galactosidases as catalysts. In this case, the fermentation with $K$. lactis allows the almost complete depletion of glucose, galactose and lactose [163]. Li et al.[164] evaluated the purification of raw GOS by treating it with immobilized cells of S. cerevisiae or K. lactis. The novelty of this purification strategy was that no nutrients for cell growth were added, thus avoiding the introduction of more pollutants. Using immobilized cells of $K$. lactis, Li et al. [164] reached a purity of $98 \%$ for two successive batches. In the same line, Hernández et al. [165] compared the selective fermentation of GOS with S. cerevisiae with other purification methodologies. Since $S$. cerevisiae lacks the $\beta$-galactosidase genes, this yeast is only capable of consuming glucose and galactose but the content of lactose remains intact. Furthermore, at prolonged fermentation time the formation of trehalose ( $\alpha$-D-glucopyranosyl-(1-1)- $\alpha$-D-glucopyranoside) is noticeable. Sangwan et al. [156] evaluated the raw GOS purification by selective fermentation with three different organisms, contacting the raw GOS in a successive manner with cells of S. cerevisiae NCDC 50, K. lactis NCDC 115 and Lactobacillus helveticus CDC 288 , achieving a purity of $92 \%$. Guerrero et al. [155] evaluated the effect of the total carbohydrate concentration on the purification of raw GOS by selective fermentation with $S$. cerevisiae and $K$. lactis. Using $K$. lactis cells a purity of $95 \%$ was obtained without diluting the raw GOS $(50 \%$ w/w) or adding some nutrients, while, with $S$. cerevisiae cells best results were obtained by diluting the raw GOS to $20 \%$ (w/w), but purity was only $39 \%$. Recently, Pázmándi et al. [154] evaluated the selective fermentation of GOS in one and two steps with Cyberlindnera jadinii NCAIM Y.00499, Kluyveromyces nonfermentans NCAIM Y.01443, Kluyveromyces marxianus DMB Km-RK and $K$. lactis DMB Kl-RK. The best results were obtained in a two-step process, where the monosaccharides were firstly depleted by $C$. jadinii NCAIM Y.00499, and then lactose was removed by $K$. lactis DMB Kl-RK. Under this configuration, a GOS purity of $92 \%$ was obtained for a $10 \%$ w/v diluted raw GOS, without GOS consumption by the yeast. On the other hand, Santibáñez et al. [166] included a prehydrolysis step with $\beta$-galactosidase to remove the unreacted 
lactose from the raw GOS before the selective fermentation, so increasing the concentration of monosaccharides which are faster consumed by K. lactis. The use of this strategy allowed to reduce the fermentation time by $40 \%$ without affecting the GOS purity achieved (96\%).

This strategy has been also used for the removal of monosaccharides in the synthesis of lactulose by transgalactosylation of fructose with lactose catalyzed by $\beta$-galactosidase. Guerrero et al. [167] evaluated the selective fermentation of raw lactulose with $S$. cerevisiae and $K$. marxianus cells reaching their total removal without adding extra nutrients. However, K. marxianus consumed part of the lactulose produced so this option was discarded. On the other hand, $S$. cerevisiae consumed only the monosaccharides, allowing to obtain a lactulose purity of $40 \%$ without diluting or nutrient addition to the $50 \% \mathrm{w} / \mathrm{w}$ raw lactulose. Similar results were obtained with commercial bakers' yeast, which is readily available at a very low cost and the cells can be reused. Julio-González et al. [125] used this strategy for the selective removal of monosaccharides in the synthesis of fGOS from lactulose. The complete removal of glucose and fructose and $70 \%$ removal of galactose was achieved after $8 \mathrm{~h}$ of fermentation with S. cerevisiae without consumption of the disaccharides and oligosaccharides; after $24 \mathrm{~h}$, all monosaccharides were completely consumed.

Other authors have reported the use of this strategy not only to increase the purity of the reacted mixtures but also to decrease the enzyme inhibition caused by monosaccharides. Aburto et al. [160] evaluated the synthesis of GOS and its simultaneous purification in one-pot mode using a biocatalyst made by entrapping $S$. cerevisiae cells and crosslinked aggregates of $A$. oryzae $\beta$-galactosidases in alginate gels. The purpose was to assess if the continuous removal of the monosaccharides increased the yield and productivity of synthesis, as well as the purity of the product, but, contrary to expected, slightly lower reaction yields and purities were obtained than in conventional batch synthesis of GOS. These results were explained by the presence of internal diffusional restrictions and the production of ethanol within the catalyst particles, which led to the formation of ethyl-galactose. Another example is the synthesis of lactosucrose from lactose and sucrose with $\beta$-fructofuranosidase: in this case, in order to remove the glucose released during the reaction, the synthesis was conducted in the presence of cells from a $S$. cerevisiae strain incapable of assimilating sucrose; enzyme inhibition was reduced and purity increased up to $70 \%$ [55, 168]. Since this strategy allows obtaining high purities at reasonable cost, [38, 88, 169], it has been adopted at industrial level by New Francisco Biotechnology Corporation, which uses the selective fermentation of raw GOS with $K$. lactis and S. cerevisiae cells for the production of the highly pure GOS preparations King-Prebiotics ${ }^{\circledR}$ GOS700P, GOS-900-P or GOS-1000-P with 70, 90 and 99\% GOS, respectively [169]. Likewise, Neo Cremar, Co. reported the use of $S$. cerevisiae cells for increasing the GOS purity from 55 to $75 \%$ in its brand product Mother's OLIGO [101].

Selective fermentation has also been reported for the purification of D-tagatose produced by D-galactose isomerization; the reacted mixture was contacted with $S$. cerevisiae cells for the removal of the unreacted galactose, which was almost completely consumed after $12 \mathrm{~h}$ of fermentation, with an increase in tagatose purity from 40 to $95 \%$ [170]. Wanarska and Kur [171] reported the production of D-tagatose from whey permeate. They expressed the $\beta$-galactosidase from Arthrobacter chlorophenolicus in Pichia pastoris. The yeast was cultured in whey-permeate to hydrolyze lactose into glucose and galactose. During this process galactose cumulated in the medium, glucose was removed by fermentation. Then D-tagatose was produced using the $\mathrm{L}$-arabinose isomerase from the psychrophile Arthrobacter sp. 22c, attaining a yield of $30 \%$. Recently, Cervantes et al. [172] reported the use of microbial fermentation to produce a D-tagatose syrup from whey permeate. Initially, lactose was hydrolyzed using $B$. bifidum $\beta$-galactosidase, and then the glucose generated was removed by contacting the hydrolyzed whey-permeate with P. pastoris cells. The authors optimized the cells concentration and fermentation time for this process, obtaining the best result at $300 \mathrm{~g} / \mathrm{L}$ and $3 \mathrm{~h}$, respectively. Afterward, the free-glucose syrup obtained was used as substrate for tagatose production with the L-arabinose isomerase from Bacillus stearothermophilus, reaching a reaction yield of $33 \%$

\section{Enzyme assisted purification}

Enzyme-conversion of the impurities has been proposed for improving the performance of a number of purification technologies. Maischberger et al. [173] studied the enzymatic transformation of the unreacted lactose during GOS synthesis into lactobionic acid. They conducted the synthesis of GOS using a recombinant $\beta$-galactosidase from $\mathrm{Lac}$ tobacillus reuteri, obtaining a product composition of 48 , 26.5 and $25.5 \%$ of monosaccharides, unreacted lactose and GOS, respectively. Since the removal of monosaccharides is easier, they successfully transformed unreacted lactose into lactobionic acid using the cellobiose dehydrogenases from Sclerotium rolfsii and Myriococcum thermophilum. Also, a laccase was used to reoxidize ABTS (2,2'-azinobis(3-ethylbenzothiazoline-6-sulfonic acid), which served as redox mediator. This strategy allowed the almost complete removal of lactose (as lactobionic acid) and monosaccharides by subsequent strong ionic exchange chromatography. However, the complexity of this strategy makes it hardly scalable. Likewise, Cordova et al. [100] evaluated the selective hydrolysis of the unreacted lactose in GOS synthesis to enhance the performance of a nanofiltration system used to remove the unwanted carbohydrates. Firstly, they conducted 
the synthesis of GOS using A. oryzae $\beta$-galactosidase, and then the selective hydrolysis of the unreacted lactose using the $K$. lactis $\beta$-galactosidase. The use of hydrolyzed raw GOS had opposite effects on nanofiltration: the permeate flux was increased by avoiding lactose-derived fouling, and reduced the GOS retention, provoking a marginal gain in purity. At large-scale, the Japanese manufacturer Yakult Pharmaceutical Industry Co., Ltd reported the use of $K$. lactis $\beta$-galactosidase to hydrolyze the unreacted lactose in GOS synthesis aiming to facilitate the downstream processing and avoid lactose crystallization in the final product [102].

As previously mentioned, Torres and Batista-Viera [77] (see Sect. 1.3.3) reported the application of S. rubiginosus D-xylose (D-glucose) isomerase for the production of D-tagatose from mozzarella cheese whey. In this case, the use of $\mathrm{D}$-xylose isomerase was intended to decrease the glucose concentration and in parallel reduce the inhibition caused on the $\beta$-galactosidase used to hydrolyze lactose, an aspect that becomes more relevant as the process is carried out in one-pot mode using individually immobilized or co-inmobilized enzymes.

Taking into account the background information presented above for the fractionation technologies of lactosederived prebiotics, the pros and cons of these technologies are summarized in Table 1. Up to now, membrane separation, adsorption, selective fermentation and enzyme-assisted purification appear as available technologies to be used at large scale for the downstream processing of lactose-derived prebiotics. Chromatography is a mature technology for the purification of carbohydrates; however, it is perceived as a relatively expensive option, so its use in this field is infrequent. In the case of GOS, it is observed that the minimum selling price of a GOS preparation exponentially increases with its purity when chromatography is the key step of the downstream processing, being selective fermentation more cost effective than chromatography to obtain highly purified ( $>95 \%$ purity) GOS preparations [88]. On the other hand, solvent precipitation is only cost-effective at laboratory scale, since the requirement of high amount of organic

Table 1 Downstream technologies for lactose-derived bioactive compounds

\begin{tabular}{|c|c|c|c|}
\hline Technology & Advantages & Disadvantages & $\begin{array}{l}\text { Remarks on prebiotic carbohydrate } \\
\text { fractioning }\end{array}$ \\
\hline Membrane separation & $\begin{array}{l}\text { Separation under mild condi- } \\
\text { tions } \\
\text { Membrane properties can be } \\
\text { tunned } \\
\text { Easy scale-up } \\
\text { Flexible operation mode (con- } \\
\text { tinuous, batch or hybrid) }\end{array}$ & $\begin{array}{l}\text { Relatively low membrane lifespan } \\
\text { Low selectivity and transmembrane } \\
\text { flux } \\
\text { Linear scale-up } \\
\text { Presence of concentration polariza- } \\
\text { tion and membrane fouling }\end{array}$ & $\begin{array}{l}\text { Usually used to remove proteins, parti- } \\
\text { cles, and microorganism } \\
\text { Difficult separation of mono- and } \\
\text { oligosaccharides with a similar } \\
\text { polymerization degree }\end{array}$ \\
\hline Chromatography & $\begin{array}{l}\text { High purity products } \\
\text { High product recovery } \\
\text { High selectivity } \\
\text { Flexible operation mode (con- } \\
\text { tinuous, batch or hybrid) } \\
\text { Low eluent consumption in } \\
\text { simulated moving bed mode } \\
\text { Wide range of sorbents and } \\
\text { mobile phase }\end{array}$ & $\begin{array}{l}\text { Dilute the product } \\
\text { Sorbent fouling } \\
\text { Expensive equipment and sorbent } \\
\text { High eluent consumption when oper- } \\
\text { ates in elution mode } \\
\text { Relatively complex scale-up }\end{array}$ & $\begin{array}{l}\text { Highly resolutive, but costly, being } \\
\text { infrequent at large-scale for oligosac- } \\
\text { charides purification }\end{array}$ \\
\hline Adsorption & $\begin{array}{l}\text { Low cost } \\
\text { Easy operation } \\
\text { Cost-effective }\end{array}$ & $\begin{array}{l}\text { Low selectivity } \\
\text { Waste generation (sorbent exhausted) } \\
\text { Sorbent preparation and regeneration } \\
\text { may be expensive }\end{array}$ & $\begin{array}{l}\text { Commonly used at large-scale because } \\
\text { it is a cost-effective technology }\end{array}$ \\
\hline Solvent precipitation & $\begin{array}{l}\text { Easy operation } \\
\text { Moderately selective (lactose) } \\
\text { Easy to scale }\end{array}$ & $\begin{array}{l}\text { Solvent recovery is needed } \\
\text { Large amount of solvent is required } \\
\text { Costly }\end{array}$ & $\begin{array}{l}\text { Very effective at lab-scale for lactose } \\
\text { removal. Hardly scalable }\end{array}$ \\
\hline Microbial selective fermentation & $\begin{array}{l}\text { Highly selective } \\
\text { High purity products } \\
\text { High product recovery }\end{array}$ & $\begin{array}{l}\text { Biomass must be produced o bought } \\
\text { Relatively costly and time-consum- } \\
\text { ing } \\
\text { Relatively complex scale-up } \\
\text { Organic side-product may be gener- } \\
\text { ated }\end{array}$ & $\begin{array}{l}\text { Used at large-scale to produce highly } \\
\text { purified preparation. Multiauxic } \\
\text { fermentation offers a highly selective } \\
\text { procedure }\end{array}$ \\
\hline Enzyme assisted purification & $\begin{array}{l}\text { Low cost } \\
\text { Highly selective } \\
\text { Easy to scale-up }\end{array}$ & Preparative step & $\begin{array}{l}\text { Chemical transformation of unwanted } \\
\text { carbohydrate(s) may significantly } \\
\text { improve the performance of the } \\
\text { downstream processing }\end{array}$ \\
\hline
\end{tabular}


solvent and the need to recover it in an industrial process, makes this technology hardly scalable.

\section{Challenges and future perspective}

Whey is no longer a nuisance but a valuable byproduct of the cheese industry. Recovery of high-quality whey proteins by membrane ultrafiltration is a well-established industrial operation and the resulting permeate is a usually underutilized lactose-rich output. Lactose per se is a low value commodity, but a valuable raw material for the production of several bioactive compounds. Functional foods are a most dynamic sector within the food industry and lactose-derived bioactives are playing an increasingly important role as functional ingredients in dairy products. They are mostly enzymatically synthesized non-digestible oligosaccharides whose present status and projections have been reviewed. Synthesis by biocatalysis is an increasingly preferred option from an environmental perspective and metrics of sustainability are in favor for replacing stoichiometric or chemically synthesized processes [174]. However, a limiting factor is the rather low reaction yields that put pressure on downstream operations, so particular emphasis was made on the different technological solutions that have been proposed to reduce the impact of downstream cost on processing cost. Among those, membrane fractionation by nanofiltration and selective fermentation of contaminant sugars are promising alternatives to replace the complex and costly chromatographic operations at industrial scale. Future looks promising as the market for functional foods containing health promoting ingredients is steadily increasing along with the growing awareness of the World population about healthier eating habits. Lactose-derived prebiotics have the advantage that lactose is a low-price commodity, sometimes in surplus, and are particularly suitable for their incorporation into dairy matrices, which seems attractive to cheese producers in terms of circular economy.

Despite some of these lactose-derived products have been in the market for some time, there is still ample room for improving such technologies by constructing better catalysts and developing low-cost downstream operations for delivering high quality products. Such advances are expected to broaden the spectrum of lactose-derived bioactive compounds that are likely to impact the market in the forthcoming decades.

\section{Conclusions}

Lactose derived from whey is a plentiful commodity usually in excess from its demand. Medium and small size cheese producers are usually confronted with the problem of proper whey management, and common practices of disposal without treatment and use for agricultural land irrigation are now being progressively banned because of environmental concern. Lactose, being the main component in whey and whey permeate, is per se of limited use because of its physicochemical and functional properties. Therefore, lactose upgrading by converting it into addedvalue products is of the utmost importance, not only from the commercial perspective of cheese producers but also for environmental considerations. Among the many strategies for lactose upgrading, its use as raw material for the production of bioactive compounds stands out. In line with the increasing concern of the world population about health eating habits, prebiotics have become important components of functional foods. Prebiotics are mostly non-digestible oligosaccharides and, among, them, those derived from lactose are mostly appealing form the viewpoint of sustainability and circular economy. Galacto-oligosaccharides, produced from lactose by enzymatic conversion, are well established prebiotic compounds being increasingly used as functional ingredients in foods, especially those derived from milk. Even though being GOS production a mature technology, there are important challenges remaining, that need to be tackled by developing enzymes better suited for performing the reaction of synthesis. and cost-effective downstream processing operations. Other lactose-derived bioactives include lactulose, epilactose, lactitol, lactobionic acid, tagatose and fructosyl-galacto-oligosaccharides, with assorted application in the food and pharmaceutical sectors. So, a platform for the efficient use of lactose within a framework of sustainability and circular economy looks quite promising, especially for developing cost-effective and sustainable technologies.

Acknowledgements This article was funded by Projects 11180282 and 1190104, National Research and Development Agency of Chile (ANID).

\section{Declarations}

Conflict of interest All the authors declare that they have no conflict of interest.

\section{References}

1. Illanes A. Whey upgrading by enzyme biocatalysis. Electron J Biotechnol. 2011. https://doi.org/10.2225/vol14-issue6-fullt ext-11.

2. Lappa I, Papadaki A, Kachrimanidou V, Terpou A, Koulougliotis D, Eriotou E, Kopsahelis N. Cheese whey processing: integrated biorefinery concepts and emerging food applications. 2019. Foods. https://doi.org/10.3390/foods8080347.

3. Chandrajith V, Karunasena G. Applications of whey as a valuable ingredient in food industry. J Dairy Vet Sci. 2018. https://doi.org/ 10.19080/JDVS.2018.06.555698. 
4. Musatti A, Cavicchioli D, Mapelli C, Bertoni D, Hogenboom JA, Pellegrino L, Rollini M. From cheese whey permeate to sakacin A: a circular economy approach for the food-grade biotechnological production of an anti-listeria bacteriocin. Biomolecules. 2020. https://doi.org/10.3390/biom10040597.

5. Zheng Z, Xie J, Liu P, Li X, Ouyang J. Elegant and efficient biotransformation for dual production of D-tagatose and bioethanol from cheese whey powder. J Agric Food Chem. 2019. https://doi. org/10.1021/acs.jafc.8b05150.

6. Geiger B, Nguyen HM, Wenig S, Nguyen HA, Lorenz C, Kittl R, Mathiesen G, Eijsink VGH, Haltrich D, Nguyen TH. From by-product to valuable components: efficient enzymatic conversion of lactose in whey using $\beta$-galactosidase from Streptococcus thermophilus. Biochem Eng J. 2016. https://doi.org/10.1016/j. bej.2016.04.003.

7. Illanes A, Guerrero C, Vera C, Wilson L, Conejeros R, Scott F. Lactose-derived prebiotics: a process perspective. 1st ed. New York: Elsevier; 2016.

8. Kaur S, Das M. Functional foods: an overview. Food Sci Biotechnol. 2011. https://doi.org/10.1007/s10068-011-0121-7.

9. Xu X, Wang Z, Zhang X. The human microbiota associated with overall health. Crit Rev Biotechnol. 2015. https://doi.org/ 10.3109/07388551.2013.819485.

10. Jędrusek-Golińska A, Górecka D, Buchowski M, WieczorowskaTobis K, Gramza-Michałowska A, Szymandera-Buszka K. Recent progress in the use of functional foods for older adults: a narrative review. Compr Rev Food Sci Food Saf. 2020. https:// doi.org/10.1111/1541-4337.12530.

11. Grochowicz J, Fabisiak A, Nowak D. Market of functional food-legal regulations and development perspectives. Zesz Probl Postępów Nauk Rol. 2018. https://doi.org/10.22630/ZPPNR. 2018.595.35.

12. Gibson GR, Hutkins R, Sanders ME, Prescott SL, Reimer RA, Salminen SJ, Scott K, Stanton C, Swanson KS, Cani PD, Verbeke K, Reid G. Expert consensus document: The International Scientific Association for Probiotics and Prebiotics (ISAPP) consensus statement on the definition and scope of prebiotics. Nat Rev Gastroenterol Hepatol. 2017. https://doi.org/10.1038/nrgas tro.2017.75.

13. Hutkins RW, Krumbeck JA, Bindels LB, Cani PD, Fahey G, Goh YJ, Hamaker B, Martens EC, Mills DA, Rastal RA, Vaughan E, Sanders ME. Prebiotics: why definitions matter. Curr Opin Biotechnol. 2016. https://doi.org/10.1016/j.copbio.2015.09.001.

14. Charalampopoulos D, Rastall RA. Prebiotics in foods. Curr Opin Biotechnol. 2012. https://doi.org/10.1016/j.copbio.2011.12.028.

15. Rastall RA, Gibson GR. Recent developments in prebiotics to selectively impact beneficial microbes and promote intestinal health. Curr Opin Biotechnol. 2015. https://doi.org/10.1016/j. copbio.2014.11.002.

16. Venema K, Van Den Abbeele P. Experimental models of the gut microbiome. Best Pract Res Clin Gastroenterol. 2013. https://doi. org/10.1016/j.bpg.2013.03.002.

17. Mackie A, Mulet-Cabero AI, Torcello-Gomez A. Simulating human digestion: developing our knowledge to create healthier and more sustainable foods. Food Funct. 2020. https://doi.org/ 10.1039/d0fo01981j.

18. Li Z, Zhu L, Zhang W, Zhan X, Gao M. New dynamic digestion model reactor that mimics gastrointestinal function. Biochem Eng J. 2020. https://doi.org/10.1016/j.bej.2019.107431.

19. Mottawea W, Sultan S, Landau K, Bordenave N, Hammami R. Evaluation of the prebiotic potential of a commercial synbiotic food ingredient on gut microbiota in an ex vivo model of the human colon. Nutrients. 2020. https://doi.org/10.3390/nu120 92669.

20. Pham VT, Mohajeri MH. The application of in vitro human intestinal models on the screening and development of pre- and probiotics. Benef Microbes. 2018. https://doi.org/10.3920/ BM2017.0164.

21. StrategyR. Prebiotics, global market trajectory \& analytics. 2021. https://www.strategyr.com/market-report-prebioticsforecasts-global-industry-analysts-inc.asp. Accessed 6 Aug 2021.

22. Martins GN, Ureta MM, Tymczyszyn EE, Castilho PC, Gomez-Zavaglia A. Technological aspects of the production of fructo and galacto-oligosaccharides. Enzymatic synthesis and hydrolysis. Front Nutr. 2019. https://doi.org/10.3389/fnut. 2019.00078.

23. Vera C, Illanes A, Guerrero C. Enzymatic production of prebiotic oligosaccharides. Curr Opin Food Sci. 2021. https://doi.org/10. 1016/j.cofs.2020.10.013.

24. Ibrahim OO. Technological aspects of fructo-oligosaccharides (FOS), production processes, physiological properties, applications and health benefits. J Food Chem Nanotechnol. 2021. https://doi.org/10.17756/jfcn.2021-111.

25. Research and Market. Inulin market-forecasts from 2020 to 2025. 2021. https://www.researchandmarkets.com/reports/5238718/ inulin-market-forecasts-from-2020-to-2025. Accessed 6 Aug 2021.

26. Research and Market. Galacto-oligosaccharide (GOS). Global market trajectory \& analytics. 2021. https://www.researchan dmarkets.com/reports/5302733/galacto-oligosaccharide-gosglobal-market. Accessed 6 Aug 2021.

27. Vera C, Guerrero C, Aburto C, Cordova A, Illanes A. Conventional and non-conventional applications of $\beta$-galactosidases. Biochim Biophys Acta-Proteins Proteom. 2020. https://doi.org/ 10.1016/j.bbapap.2019.140271.

28. Nooshkam M, Babazadeh A, Jooyandeh H. Lactulose: properties, techno-functional food applications, and food grade delivery system. Trends Food Sci Technol. 2018. https://doi.org/10.1016/j. tifs.2018.07.028

29. Chen C, Deng J, Lv X, Li J, Du G, Li H, Liu L. Biocatalytic synthesis of lactosucrose using a recombinant thermostable $\beta$-fructofuranosidase from Arthrobacter sp. 10138. Bioengineered. 2020. https://doi.org/10.1080/21655979.2020.1739404.

30. Zhang W, Chen J, Chen Q, Wu H, Mu W. Sugar alcohols derived from lactose: lactitol, galactitol, and sorbitol. Appl Microbiol Biotechnol. 2020. https://doi.org/10.1007/s00253-020-10929-w.

31. Cardoso T, Marques C, Dagostin JLA, Masson ML. Lactobionic acid as a potential food ingredient: recent studies and applications. J Food Sci. 2019. https://doi.org/10.1111/1750-3841. 14686.

32. Sokołowska E, Sadowska A, Sawicka D, Kotulska-Bąblińska I, Car H. A head-to-head comparison review of biological and toxicological studies of isomaltulose, D-tagatose, and trehalose on glycemic control. Crit Rev Food Sci Nutr. 2021. https://doi. org/10.1080/10408398.2021.1895057.

33. Guerrero C, Vera C, Illanes A. Optimisation of synthesis of oligosaccharides derived from lactulose (fructosyl-galacto-oligosaccharides) with $\beta$-galactosidases of different origin. Food Chem. 2013. https://doi.org/10.1016/j.foodchem.2012.10.128.

34. Logtenberg MJ, Akkerman R, Hobé RG, Donners KMH, Van Leeuwen SS, Hermes GDA, de Haan BJ, Faas MM, Buwalda PL, Zoetendal EG, de Vos P, Schols HA. Structure-specific fermentation of galacto-oligosaccharides, isomalto-oligosaccharides and isomalto/malto-polysaccharides by infant fecal microbiota and impact on dendritic cell cytokine responses. Mol Nutr Food Res. 2021. https://doi.org/10.1002/mnfr.202001077.

35. Arnold JW, Roach J, Fabella S, Moorfield E, Ding S, Blue E, Dagher S, Magness S, Tamayo R, Bruno-Barcena JM, AzcaratePeril MA. The pleiotropic effects of prebiotic galacto-oligosaccharides on the aging gut. Microbiome. 2021. https://doi.org/10. 1186/s40168-020-00980-0. 
36. Hanson S, Best M, Bryan MC, Wong CH. Chemoenzymatic synthesis of oligosaccharides and glycoproteins. Trends Biochem Sci. 2004. https://doi.org/10.1016/j.tibs.2004.10.004.

37. Vera C, Guerrero C, Conejeros R, Illanes A. Synthesis of galacto-oligosaccharides by $\beta$-galactosidase from Aspergillus oryzae using partially dissolved and supersaturated solution of lactose. Enzyme Microb Technol. 2012. https://doi.org/10. 1016/j.enzmictec.2011.12.003.

38. Kruschitz A, Nidetzky B. Downstream processing technologies in the biocatalytic production of oligosaccharides. Biotechnol Adv. 2020. https://doi.org/10.1016/j.biotechadv.2020.107568.

39. Sakai Y, Seki N, Hamano K, Ochi H, Abe F, Masuda K, Iino H. Prebiotic effect of two grams of lactulose in healthy Japanese women: a randomised, double-blind, placebo-controlled crossover trial. Benef Microbes. 2019. https://doi.org/10.3920/ BM2018.0174.

40. Panesar PS, Kumari S. Lactulose: production, purification and potential applications. Biotechnol Adv. 2011. https://doi.org/ 10.1016/j.biotechadv.2011.08.008.

41. Sitanggang AB, Drews A, Kraume M. Recent advances on prebiotic lactulose production. World J Microbiol Biotechnol. 2020. https://doi.org/10.1007/s11274-016-2103-7.

42. Guerrero C, Vera C, Conejeros R, Illanes A. Transgalactosylation and hydrolytic activities of commercial preparations of $\beta$-galactosidase for the synthesis of prebiotic carbohydrates. Enzyme Microb Technol. 2015. https://doi.org/10.1016/j.enzmi ctec.2014.12.006.

43. Guerrero C, Aburto C, Súarez S, Vera C, Illanes A. Improvements in the production of Aspergillus oryzae $\beta$-galactosidase crosslinked aggregates and their use in repeated-batch synthesis of lactulose. Int J Biol Macromol. 2020. https://doi.org/10. 1016/j.ijbiomac.2019.09.117.

44. Julio-Gonzalez LC, Hernández-Hernández O, Javier Moreno F, Olano A, Corzo N. High-yield purification of commercial lactulose syrup. Sep Purif Technol. 2019. https://doi.org/10. 1016/j.seppur.2019.05.053.

45. Guerrero C, Vera C, Plou F, Illanes A. Influence of reaction conditions on the selectivity of the synthesis of lactulose with microbial $\beta$-galactosidases. J Mol Catal B Enzym. 2011. https://doi.org/10.1016/j.molcatb.2011.06.007.

46. Kim YS, Oh DK. Lactulose production from lactose as a single substrate by a thermostable cellobiose 2-epimerase from Caldicellulosiruptor saccharolyticus. Bioresour Technol. 2012. https://doi.org/10.1016/j.biortech.2011.11.016.

47. Shen S, Zhang Y, Yang R, Hua X, Zhang W, Zhao W. Thermostability enhancement of cellobiose 2-epimerase from $\mathrm{Cal}$ dicellulosiruptor saccharolyticus by site-directed mutagenesis. J Mol Catal B Enzym. 2015. https://doi.org/10.1016/j.molcatb. 2015.07.007.

48. Shen Q, Zhang Y, Yang R, Pan S, Dong J, Fan Y, Han L. Enhancement of isomerization activity and lactulose production of cellobiose 2-epimerase from Caldicellulosiruptor saccharolyticus. Food Chem. 2016. https://doi.org/10.1016/j.foodc hem.2016.02.067.

49. Chen Q, Xiao Y, Zhang W, Zhang T, Jiang B, Stressler T, Fischer L, Mu W. Current research on cellobiose 2-epimerase: enzymatic properties, mechanistic insights, and potential applications in the dairy industry. Trends Food Sci Technol. 2018. https://doi.org/10.1016/j.tifs.2018.09.009.

50. O'Brien J. Non-Enzymatic degradation pathways of lactose and their Significance in dairy products. In: McSweeney P, Fox P, editors. Advanced dairy chemistry. New York: Springer; 2009. p. 231-94. https://doi.org/10.1007/978-0-387-84865-5_7.

51. Watanabe J, Nishimukai M, Taguchi H, Senoura T, Hamada S, Matsui H, Yamamoto T, Wasaki J, Hara H, Ito S. Prebiotic properties of epilactose. J Dairy Sci. 2008. https://doi.org/10. 3168/jds.2008-1367.

52. Chen Q, Xiao Y, Wu Y. Characteristics of cellobiose 2-epimerase and its application in enzymatic production of lactulose and epilactose. In: Mu W, Zhang W, Chen Q, editors. Novel enzymes for functional carbohydrates production. Singapure: Springer; 2021. p. 105-23. https://doi.org/10.1007/ 978-981-33-6021-1_6.

53. Krewinkel M, Gosch M, Rentschler E, Fischer L. Epilactose production by 2 cellobiose 2 -epimerases in natural milk. J. Dairy Sci. 2014. https://doi.org/10.3168/jds.2013-7389.

54. Chen Q, He W, Yan X, Zhang T, Jiang B, Stressler T, Fischer L, $\mathrm{Mu}$ W. Construction of an enzymatic route using a food-grade recombinant Bacillus subtilis for the production and purification of epilactose from lactose. J. Dairy Sci. 2018. https://doi. org/10.3168/jds.2017-12936.

55. Silvério SC, Macedo EA, Teixeira JA, Rodrigues LR. Perspectives on the biotechnological production and potential applications of lactosucrose: a review. J Funct Foods. 2015. https:// doi.org/10.1016/j.jff.2015.09.014.

56. Duarte LS, Schöffer JN, Lorenzoni ASG, Rodrigues RC, Rodrigues $\mathrm{E}$, Hertz PF. A new bioprocess for the production of prebiotic lactosucrose by an immobilized $\beta$-galactosidase. Process Biochem. 2017. https://doi.org/10.1016/j.procbio.2017.01. 015 .

57. Martinez-Monteagudo SI, Enteshari M, Metzger L. Lactitol: production, properties, and applications. Trends Food Sci Technol. 2019. https://doi.org/10.1016/j.tifs.2018.11.020.

58. Sarenkova L, Ciprovica I. The current status and future perspectives of lactobionic acid production: a review. Rural Dev. 2018. https://doi.org/10.22616/rrd.24.2018.037.

59. Pedruzzi L, Borges da Silva EA, Rodrigues AE. Production of clear lactobionic acid and sorbitol from lactose/fructose substrate using GFOR/GL enzymes from Zymomonas mobilis cells: akinetic study. Enzyme Microb Technol. 2011. https:// doi.org/10.1016/j.enzmictec.2011.04.017.

60. Tian Q, Feng Y, Huang H, Zhang J, Yu Y, Guan Z, Cai Y, Liao $\mathrm{X}$. Production of lactobionic acid from lactose using the cellobiose dehydrogenase-3-HAA-laccase system from Pycnoporus sp. SYBC-L10. Lett Appl Microbiol. 2018. https://doi.org/10. 1111/lam.13070.

61. Alonso S, Rendueles M, Diaz M. Efficient lactobionic acid production from whey by pseudomonas taetrolens under $\mathrm{pH}$ shift conditions. Bioresour Technol. 2011. https://doi.org/10. 1016/j.biortech.2011.07.089.

62. Alonso S. Exploiting the bioengineering versatility of lactobionic acid in targeted nanosystems and biomaterials. J Control Release. 2018. https://doi.org/10.1016/j.jconrel.2018.08.030.

63. Beadle JR, Saunders JP, Thomas J, Wajda J (1992) Process for manufacturing tagatose. United States Patent. US5078796A.

64. Roy S, Chikkerur J, Roy SC, Dhali A, Kolte AP, Sridhar M, Samanta AK. Tagatose as a potential nutraceutical: production, properties, biological roles, and applications. J Food Sci. 2018. https://doi.org/10.1111/1750-3841.14358.

65. Izumori K, Miyoshi T, Tokuda S, Yamabe K. Production of D-tagatose from dulcitol by Arthrobacter globiformis. Appl Environ Microbiol. 1984. https://doi.org/10.1128/aem.48.5.10551057.1984

66. Yoshihara K, Shinohara Y, Hirotsu T, Izumori K. Bioconversion of D-psicose to D-tagatose and D-talitol by Mucoraceae fungi. J Biosci Bioeng. 2006. https://doi.org/10.1263/jbb.101.219.

67. Jagtap SS, Singh R, Kang YC, Zhao H, Lee JK. Cloning and characterization of a galactitol 2-dehydrogenase from Rhizobium legumenosarum and its application in d-tagatose production. Enzyme Microb Technol. 2014. https://doi.org/10.1016/j. enzmictec.2014.02.012. 
68. Lee DW, Jang HJ, Choe EA, Kim BC, Lee SJ, Kim SB, Hong YH, Pyun YR. Characterization of a thermostable L-arabinose (D-galactose) isomerase from the hyperthermophilic eubacterium Thermotoga maritima. Appl Environ Microbiol. 2004. https://doi.org/10.1128/AEM.70.3.1397-1404.2004.

69. Ravikumar Y, Ponpandian LN, Zhang G, Yun J, Qi X. Harnessing $\mathrm{L}$-arabinose isomerase for biological production of D-tagatose: recent advances and its applications. Trends Food Sci Technol. 2021. https://doi.org/10.1016/j.tifs.2020.11.020.

70. Kim HJ, Kim JH, Oh HJ, Oh DK. Characterization of a mutated Geobacillus stearothermophilus L-arabinose isomerase that increases the production rate of D-tagatose. J Appl Microbiol. 2006. https://doi.org/10.1111/j.1365-2672.2006.02975.x.

71. Rhimi M, Aghajari N, Juy M, Chouayekh H, Maguin E, Haser $\mathrm{R}$, Bejar S. Rational design of Bacillus stearothermophilus US100 L-arabinose isomerase: potential applications for D-tagatose production. Biochimie. 2009. https://doi.org/10. 1016/j.biochi.2009.01.014.

72. de Sousa M, Melo VMM, Hissa DC, Manzo RM, Mammarella EJ, Antunes ASLM, Garcia JL, Pessela BC, Goncalves LRB. One-step immobilization and stabilization of a recombinant Enterococcus faecium DBFIQ E36 L-arabinose isomerase for D-tagatose synthesis. Appl Biochem Biotechnol. 2019. https:// doi.org/10.1007/s12010-018-2905-1.

73. Jayamuthunagai J, Srisowmeya G, Chakravarthy M, Gautam P. D-Tagatose production by permeabilized and immobilized Lactobacillus plantarum using whey permeate. Bioresour Technol. 2017. https://doi.org/10.1016/j.biortech.2017.03.123.

74. Khuwijitjaru P, Milasing N, Adachi S. Production of D-tagatose: A review with emphasis on subcritical fluid treatment. Sci: Eng Heal Stud. 2018. https://doi.org/10.14456/sehs.2018. 15.

75. Bortone N, Fidaleo M. Stabilization of immobilized L-arabinose isomerase for the production of D-tagatose from D-galactose. Biotechnol Prog. 2020. https://doi.org/10.1002/btpr.3033.

76. Torres P, Batista-Viera F. Immobilized trienzymatic system with enhanced stabilization for the biotransformation of lactose. Molecules. 2017. https://doi.org/10.3390/molecules2 2020284.

77. Torres P, Batista-Viera F. Production of D-tagatose and D-fructose from whey by co-immobilized enzymatic system. Mol Catal. 2019. https://doi.org/10.1016/j.mcat.2018.11.017.

78. Torrico D, Tam J, Fuentes S, Gonzalez C, Dunshea FR. D-Tagatose as a sucrose substitute and its effect on the physicochemical properties and acceptability of strawberry-flavored yogurt. Foods. 2019. https://doi.org/10.3390/foods8070256.

79. Ensor E, Banfield AB, Smith RR, Williams J, Lodder RA. Safety and efficacy of D-tagatose in glycemic control in subjects with type 2 diabetes. J Endocrinol Diabetes Obes. 2015;3:1065.

80. Jayamuthunagai J, Gautam P, Srisowmeya G, Chakravarthy M. Biocatalytic production of D-tagatose: a potential rare sugar with versatile applications. Crit Rev Food Sci Nutr. 2017. https://doi. org/10.1080/10408398.2015.1126550.

81. Lee SH, Hong SH, An JU, Kim KR, Kim DE, Kang LW, Oh DK. Structure-based prediction and identification of 4-epimerization activity of phosphate sugars in class II aldolases. Sci Rep. 2017. https://doi.org/10.1038/s41598-017-02211-3.

82. Food Safety Authority of Ireland. Substantial equivalence opinion: D-tagatose, Dublin. 2016. https://www.fsai.ie/uploadedFiles/ Science_and_Health/Novel_Foods/Notifications/Substantial\% 20equivalence\%20opinion(1).pdf. Accessed 12 Sep 2021.

83. Lee Y, Park I, Shin S, Yang S, Cho H, Kim S, Choi E. A fructoseC4-epimerase and preparation methods for producing tagatose using the same, US 2020/0263217 A1. 2020.

84. Martinez-Villaluenga C, Cardelle-Cobas A, Olano A, Corzo N, Villamiel M, Jimeno ML. Enzymatic synthesis and identification of two trisaccharides produced from lactulose by transgalactosylation. J Agric Food Chem. 2008. https://doi. org/10.1021/jf0721343.

85. Cardelle-Cobas A, Olano A, Corzo N, Villamiel M, Collins M, Kolida S, Rastall R. In vitro fermentation of lactulose derived oligosaccharides by mixed faecal microbiota. J Agric Food Chem. 2012. https://doi.org/10.1021/jf203622d.

86. Padilla B, Ruiz-Matute AI, Belloch C, Cardelle-Cobas A, Corzo N, Manzanares P. Evaluation of oligosaccharide synthesis from lactose and lactulose using $\beta$-galactosidases from Kluyveromyces isolated from artisanal cheeses. J Agric Food Chem. 2012. https://doi.org/10.1021/jf300852s.

87. Fernandez J, Moreno FJ, Olano A, Clemente A, Villar CJ, Lombo F. A galacto-oligosaccharides preparation derived from lactulose protects against colorectal cancer development in an animal model. Front Microbiol. 2018. https://doi.org/10.3389/fmicb. 2018.02004.

88. Scott F, Vera C, Conejeros R. Technical and economic analysis of industrial production of lactose-derived prebiotics with focus on galacto-oligosaccharides. In: Illanes A, Guerrero C, Vera C, Wilson L, Conejeros R, Scott F, editors. Lactose-derived prebiotics: a process perspective. New York: Elsevier; 2016. p. 261-84.

89. Ganzle MG, Haase G, Jelen P. Lactose: crystallization, hydrolysis and value-added derivatives. Int Dairy J. 2008. https://doi.org/ 10.1016/j.idairyj.2008.03.003.

90. Benkoulouche M, Faure R, Remaud-Simeon M, Moulis C, Andre I. Harnessing glycoenzyme engineering for synthesis of bioactive oligosaccharides. Interface Focus. 2019. https://doi.org/10.1098/ rsfs.2018.0069.

91. Downey AM, Hocek M. Strategies toward protecting group free glycosylation through selective activation of the anomeric center. Beilstein J Org Chem. 2017. https://doi.org/10.3762/bjoc.13.123.

92. Cordova A, Astudillo C, Illanes A. Membrane technology for the purification of enzymatically produced oligosaccharides. In: Galanakis CM, editor. Separation of functional molecules in food by membrane technology. New York: Elsevier; 2018. p. 113-53.

93. Wheelwright SM. The design of downstream processes for large scale protein purification. J Biotechnol. 1989. https://doi.org/10. 1016/0168-1656(89)90112-0.

94. Łącki KM, Joseph J, Eriksson KO. Downstream process design, scale-up principles, and process Modeling. In: Jagschies G, Lindskog E, Łąck K, Galliher P, editors. Biopharmaceutical processing development, design, and implementation of manufacturing processes. New York: Elsevier; 2018. p. 637-74.

95. Charcosset C. Classical and recent applications of membrane processes in the food industry. Food Eng Rev. 2021. https://doi. org/10.1007/s12393-020-09262-9.

96. Argenta AB, Scheer ADP. Membrane separation processes applied to whey: a review. Food Rev Int. 2020. https://doi.org/ 10.1080/87559129.2019.1649694.

97. D'Souza NM, Mawson AJ. Membrane cleaning in the dairy industry: a review. Crit Rev Food Sci Nutr. 2005. https://doi. org/10.1080/10408690490911783.

98. Aguirre Montesdeoca V, Van der Padt A, Boom RM, Janssen AEM. Modelling of membrane cascades for the purification of oligosaccharides. J Memb Sci. 2016. https://doi.org/10.1016/j. memsci.2016.08.031.

99. Saleh TA, Gupta VK. An Overview of Membrane science and technology. In: Saleh TA, Vinod KG, editors. Nanomaterial and polymer membranes synthesis, characterization, and applications. New York: Elsevier; 2016. p. 1-23.

100. Cordova A, Astudillo C, Santibanez L, Cassano A, RubyFigueroa R, Illanes A. Purification of galacto-oligosaccharides (GOS) by three-stage serial nanofiltration units under critical transmembrane pressure conditions. Chem Eng Res Des. 2017. https://doi.org/10.1016/j.cherd.2016.11.006. 
101. GRAS Associates. Gras notice 729. Galactooligosaccharides (GOS), food usage conditions for general recognition of safety. 2017. https://www.fda.gov/media/111860/download . Accessed1 Sept 2021.

102. Spherix Consulting Inc. Gras notice 334 . Generally recognized as safe (GRAS) determination for the use of galacto-oligosaccharides (GOS) in foods and infant formulas. 2010. http://wayba ck.archive-it.org/7993/20171031050145/. https://www.fda.gov/ downloads/Food/IngredientsPackagingLabeling/GRAS/Notic eInventory/UCM269519.pdf. Accessed 1 Sep 2021.

103. Singh R. Introduction to membrane technology. Hybrid Membrane Systems for Water Purification. 2005. https://doi.org/10. 1016/b978-185617442-8/50002-6.

104. Nestle Nutrition U.S. GRAS notice 620. GRAS Exemption Claim for Galacto-ligosaccharides. 2016. https://wayback.archive-it. org/7993/20190208035755/. Accessed 1 Sept 2021.

105. Clasado Inc. GRAS Notice 484. GRAS Exemption Claim for Galacto-oligosaccharides. 2013. http://wayback.archive-it.org/ 7993/20171031055001/. Accessed 1 Sept 2021.

106. Friesland Foods Domo. Gras notice 236. GRAS exemption claim for galacto-oligosaccharides (GOS). 2007. https://wayback.archi ve-it.org/7993/20190208035755/. Accessed 1 Sept 2021.

107. Cordova A, Astudillo C, Giorno L, Guerrero C, Conidi C, Illanes A, Cassano A. Nanofiltration potential for the purification of highly concentrated enzymatically produced oligosaccharides. Food Bioprod. Process. 2016. https://doi.org/10.1016/j.fbp.2015. 11.005 .

108. Gonzalez-Delgado I, Lopez-Munoz MJ, Morales G, Segura Y. Optimisation of the synthesis of high galacto-oligosaccharides (GOS) from lactose with $\beta$-galactosidase from Kluyveromyceslactis. Int Dairy J. 2016. https://doi.org/10.1016/j.idairyj.2016. 06.007.

109. Goulas AK, Kapasakalidis PG, Sinclair HR, Rastall R, Grandison AS. Purification of oligosaccharides by nanofiltration. J Memb Sci. 2002. https://doi.org/10.1016/S0376-7388(02)00362-9.

110. Michelon M, Minera AP, Carvalho AL, Maugeri FF. Concentration and purification of galacto-oligosaccharides using nanofiltration membranes. Int J Food Sci Technol. 2014. https://doi.org/ 10.1111/ijfs. 12582.

111. Ren H, Fei J, Shi X, Zhao T, Cheng H, Zhao N, Chen Y, Ying $\mathrm{H}$. Continuous ultrafiltration membrane reactor coupled with nanofiltration for the enzymatic synthesis and purification ofgalactosyl-oligosaccharides. Sep Purif Technol. 2015. https://doi. org/10.1016/J.SEPPUR.2015.02.020.

112. Pruksasri S, Nguyen TH, Haltrich D, Novalin S. Fractionation of a galacto-oligosaccharides solution at low and high temperature using nanofiltration. Sep Purif Technol. 2015. https://doi.org/10. 1016/j.seppur.2015.07.015.

113. Wiśniewski Ł, Pereira CSM, Polakovič M, Rodrigues AE. Chromatographic separation of prebiotic oligosaccharides. Case study: separation of galacto-oligosaccharides on a cation exchanger. Adsorption. 2014. https://doi.org/10.1007/s10450-013-9587-3.

114. Wiśniewski $Ł$, Antošova M, Polakovič M. Simulated moving bed chromatography separation of galacto-oligosaccharides. Acta Chim Slovaca. 2013. https://doi.org/10.2478/acs-2013-0033.

115. Mueller I, Seidel-Morgenstern A, Hamel C. Simulated-moving bed technology for purification of the prebiotics galacto-oligosaccharides. Sep Purif Technol. 2021. https://doi.org/10.1016/j. seppur.2021.118829.

116. Nagy G, Peng T, Pohl NLB. Recent liquid chromatographic approaches and developments for the separation and purification of carbohydrates. Anal Methods. 2017. https://doi.org/10. 1039/C7AY01094J.
117. Buszewski B, Noga S. Hydrophilic interaction liquid chromatography (HILIC) - a powerful separation technique. Anal Bioanal Chem. 2012. https://doi.org/10.1007/s00216-011-5308-5.

118. Cooper WT. Normal-phase liquid chromatography. In: Meyers RA, editor. Encyclopedia of analytical chemistry: applications, theory and instrumentation. Chichester: Wiley; 2006. https://doi. org/10.1002/9780470027318.a5913.

119. Moldoveanu SC, David V. Basic information about HPLC. In: Moldoveanu SC, editor. Essentials in modern HPLC separations. New York: Elsevier; 2013. p. 1-51.

120. Brereton KR, Green DB. Isolation of saccharides in dairy and soy products by solid-phase extraction coupled with analysis by ligand-exchange chromatography. Talanta. 2012. https://doi.org/ 10.1016/j.talanta.2012.08.003.

121. Stefansson M, Westerlund D. Ligand-exchange chromatography of carbohydrates and glycoconjugates. J Chromatogr A. 1996. https://doi.org/10.1016/0021-9673(95)00276-6.

122. Wach W, Fornefett I, Buttersack C, Buchholz K. Adsorption and HPLC of carbohydrates and related hydroxy compounds on zeolites. Anal. Methods. 2018. https://doi.org/10.1039/c7ay02634j.

123. Wach W, Buttersack C, Buchholz K. Chromatography of mono and disaccharides on granulated pellets of hydrophobic zeolites. J Chromatogr A. 2018. https://doi.org/10.1016/j.chroma.2018. 09.040 .

124. Kuhn RC, Filho FM. Purification of fructooligosaccharides in an activated charcoal fixed bed column. N Biotechnol. 2010. https:// doi.org/10.1016/j.nbt.2010.05.008.

125. Julio-Gonzalez LC, Ruiz-Aceituno L, Corzo N, Olano A. Purification of lactulose derived-galactooligosaccharides from enzymatic reaction mixtures. Int Dairy J. 2018. https://doi.org/10. 1016/j.idairyj.2018.04.013.

126. Wolfgang J, Prior A, Bart HJ, Messenbock RC, Byers CH. Continuous separation of carbohydrates by ion-exchange chromatography. Sep Sci Technol. 1997. https://doi.org/10.1080/01496 399708003187.

127. Rajendran A, Paredes G, Mazzotti M. Simulated moving bed chromatography for the separation of enantiomers. J Chromatogr A. 2009. https://doi.org/10.1016/j.chroma.2008.10.075.

128. Nicoud RM. Simulated moving-bed chromatography for biomolecules.In. In: Ahuja S, editor. Handbook of Bioseparations. London: Academic Press; 2000. p. 475-509.

129. Dendene K, Guihard L, Balannec B, Bariou B. Study of the separation of lactose, lactulose and galactose by liquid chromatography using cationic ion-exchange resin columns. Chromatographia. 1995. https://doi.org/10.1007/BF02688086.

130. Kozempel MF, Kurantz MJ, Craig JC, Hicks KB. Development of a continuous lactulose process: separation and purification. Biotechnol Prog. 1995. https://doi.org/10.1021/bp00035a015.

131. Tamura A, Sha Y, Adachi S. Effects of counter-ion form of a cation-exchange resin and ethanol content of eluent on the distribution coefficients of galactose, tagatose, and talose onto the resin. Food Sci Technol Res. 2016. https://doi.org/10.3136/fstr. 22.205.

132. Pedruzzi I, da Silva EAB, Rodrigues AE. Selection of resins, equilibrium and sorption kinetics of lactobionic acid, fructose, lactose and sorbitol. Sep Purif Technol. 2008. https://doi.org/10. 1016/j.seppur.2008.07.001.

133. Kawase M, Pilgrim A, Araki T, Hashimoto K. Lactosucrose production using a simulated moving bed reactor. Chem Eng Sci. 2001. https://doi.org/10.1016/S0009-2509(00)00248-7.

134. Pilgrim A, Kawase M, Matsuda F, Miura K. Modeling of the simulated moving-bed reactor for the enzyme-catalyzed production of lactosucrose. Chem Eng Sci. 2006. https://doi.org/10.1016/j. ces.2005.07.012. 
135. GTC Nutrition. GRAS notice 285. Galactooligosaccharide GRAS notice. 2009. http://wayback.archive-it.org/7993/20171 031055001/. https://www.fda.gov/downloads/Food/Ingredient sPackagingLabeling/GRAS/NoticeInventory/ucm269255.pdf. Accessed 1 Sept 2021.

136. Nutrasource Inc. GRAS notice 352. GRAS exemption claim for D-tagatose as an ingredient in foods. 2010. http://wayback.archi ve-it.org/7993/20171031055001/. https://www.fda.gov/downl oads/Food/IngredientsPackagingLabeling/GRAS/NoticeInve ntory/ucm269560.pdf. Accessed 1 Sept 2021.

137. Cossu R, Ehrig HJ, Muntoni A. Physical-chemical leachate treatment. In: Cossu R, Rainer S, editors. Solid waste landfilling. New York: Elsevier; 2018. p. 575-632.

138. $\mathrm{Hu} \mathrm{H}, \mathrm{Xu} \mathrm{K}$. Physicochemical technologies for HRPs and risk control. In: Ren H, Zhang X, editors. High-risk pollutants in wastewater. New York: Elsevier; 2020. p. 169-207.

139. Doran PM. Bioprocess engineering principles. 2nd ed. New York: Elsevier; 2013. p. 445-595.

140. Harcum S. Purification of protein solutions. In: Abbott A, Ellison M, editors. Biologically inspired textiles. 1st ed. New York: Elsevier; 2008. p. 26-43.

141. Ayawei N, Ebelegi AN, Wankasi D. Modelling and interpretation of adsorption isotherms. J Chem. 2017. https://doi.org/10.1155/ 2017/3039817.

142. Ji D, Sims I, Xu M, Stewart I, Agyei D. Production and identification of galacto-oligosaccharides from lactose using $\beta$-Dgalactosidases from Lactobacillus leichmannii 313. Carbohydr Polym Technol Appl. 2021. https://doi.org/10.1016/j.carpta. 2021.100038.

143. Van Velthuijsen JA. Food additives derived from lactose: lactitol and lactitol palmitate. J Agric Food Chem. 1979. https://doi.org/ 10.1021/jf60224a040.

144. Vera C, Illanes A. Lactose-derived nondigestible oligosaccharides and other high added-value products. In: Illanes A, Conejeros R, Scott F, Guerrero C, Vera C, Wilson L, editors. Lactosederived prebiotics: a process perspective. New York: Elsevier; 2016. p. 87-110.

145. Boon MA, Vant Riet K, Janssen AEM. Enzymatic synthesis of oligosaccharides: product removal during a kinetically controlled reaction. Biotechnol Bioeng. 2000. https://doi.org/10.1002/10970290(20001120)70:43.0.CO;2-W.

146. Vera C, Guerrero C, Illanes A. Determination of the transgalactosylation activity of Aspergillus oryzae $\beta$-galactosidase: effect of $\mathrm{pH}$, temperature, and galactose and glucose concentrations. Carbohydr Res. 2011. https://doi.org/10.1016/j.carres.2011.01. 030 .

147. Albayrak N, Yang ST. Production of galacto-oligosaccharides from lactose by Aspergillus oryzae $\beta$-galactosidase immobilized on cotton cloth. Biotechnol Bioeng. 2002. https://doi.org/10. 1002/bit.1195.

148. Hu X, Liu C, Jin Z, Tian Y. Fractionation of starch hydrolysate into dextrin fractions with low dispersity by gradient alcohol precipitation. Sep Purif Technol. 2015. https://doi.org/10.1016/j. seppur.2015.07.044.

149. Sen D, Gosling A, Stevens GW, Bhattacharya PK, Barber AR, Kentish SE, Bhattacharjee C, Gras SL. Galactosyl oligosaccharide purification by ethanol precipitation. Food Chem. 2011. https://doi.org/10.1016/j.foodchem.2011.03.076.

150. Oosten BJ. Solubility diagram of lactose and lactulose in water. Recl Des Travr Chim Des Pays-Bas. 1967. https://doi.org/10. 1002/recl.19670860614.

151. Zanganeh N, Zabet M. Studying the effect of ethanol and operating temperature on purification of lactulose syrup containing lactose. World Acad Sci Eng Technol Int J Biol Biomol Agric Food Biotechnol Eng. 2015. https://doi.org/10.5281/zenodo.1126149.
152. Montanes F, Olano A, Ibanez E, Fornari T. Modeling solubilities of sugars in alcohols based on original experimental data. AIChE J. 2007. https://doi.org/10.1002/aic.11258.

153. Lee SH, Hong SH, Kim KR, Oh DK. High-yield production of pure tagatose from fructose by a three-step enzymatic cascade reaction. Biotechnol Lett. 2017. https://doi.org/10.1007/ s10529-017-2340-3.

154. Pazmandi M, Kovacs Z, Balga E, Kovacs M, Maraz A. Production of high-purity galacto-oligosaccharides by depleting glucose and lactose from galacto-oligosaccharide syrup with yeasts. Yeast. 2020. https://doi.org/10.1002/yea.3507.

155. Guerrero C, Vera C, Novoa C, Dumont J, Acevedo F, Illanes A. Purification of highly concentrated galacto-oligosaccharide preparations by selective fermentation with yeasts. Int Dairy J. 2014. https://doi.org/10.1016/j.idairyj.2014.05.011.

156. Sangwan V, Tomar SK, Ali B, Singh RRB, Singh AK, Mandal S. Galactooligosaccharides purification using microbial fermentation and assessment of its prebiotic potential by in vitro method. Int J Curr Microbiol App Sci. 2014;3:573-85.

157. Gancedo JM. Carbon catabolite repression in yeast. Eur J Biochem. 1992. https://doi.org/10.1111/j.1432-1033.1992.tb169 28.x.

158. Bruckner R, Titgemeyer F. Carbon catabolite repression in bacteria: Choice of the carbon source and autoregulatory limitation of sugar utilization. FEMS Microbiol Lett. 2002. https://doi.org/ 10.1016/S0378-1097(02)00559-1.

159. Simpson-Lavy K, Kupiec M. Carbon Catabolite Repression in yeast is not limited to Glucose. Sci Rep. 2019. https://doi.org/10. 1038/s41598-019-43032-w.

160. Aburto C, Guerrero C, Vera C, Wilson L, Illanes A. Co-immobilized $\beta$-galactosidase and Saccharomyces cerevisiae cells for the simultaneous synthesis and purification of galacto-oligosaccharides. Enzym Microb Technol. 2018. https://doi.org/10.1016/j. enzmictec.2018.08.003.

161. Onishi N, Tanaka T. Galacto-oligosaccharide production using a recycling cell culture of Sterigmatomyces elviae CBS8119. Lett Appl Microbiol. 1998. https://doi.org/10.1046/j.1472-765X. 1998.00293.x.

162. Onishi N, Yamashiro A, Yokozeki K. Production of galacto-oligosaccharide from lactose by Sterigmatomyces elviae CBS8119. Appl Environ Microbiol. 1995. https://doi.org/10.1128/aem.61. 11.4022-4025.1995.

163. Cheng CC, Yu MC, Cheng TC, Sheu DC, Duan KJ, Tai WL. Production of high-content galacto-oligosaccharide by enzyme catalysis and fermentation with Kluyveromyces marxianus. BiotechnolLett. 2006. https://doi.org/10.1007/s10529-006-9002-1.

164. Li Z, Xiao M, Lu L, Li Y. Production of non-monosaccharide and high-purity galactooligosaccharides by immobilized enzyme catalysis and fermentation with immobilized yeast cells. Process Biochem. 2008. https://doi.org/10.1016/j.procbio.2008.04.016.

165. Hernandez O, Ruiz-Matute AI, Olano A, Moreno FJ, Sanz ML. Comparison of fractionation techniques to obtain prebiotic galactooligosaccharides. Int Dairy J. 2009. https://doi.org/10.1016/j. idairyj.2009.03.002.

166. Santibanez L, Guerrero C, Illanes A. Raw galacto-oligosaccharide purification by consecutive lactose hydrolysis and selective bioconversion. Int Dairy J. 2017. https://doi.org/10.1016/j.idair yj.2017.07.008.

167. Guerrero C, Vera C, Illanes A. Selective bioconversion with yeast for the purification of raw lactulose and transgalactosylated oligosaccharides. Int Dairy J. 2018. https://doi.org/10.1016/j.idair yj.2018.02.003. 
168. Okabe T, Aga H, Kunota H, Miyake M. Lactosucrose high content saccharide, its preparation and uses. U.S. 20080027027A1. 2008.

169. Soni \& Associates Inc. GRAS notice 569. GRAS Notification for galacto-oligosaccharide (infant formula use). 2015. http://wayba ck.archive-it.org/7993/20171031055001/. https://www.fda.gov/ downloads/Food/IngredientsPackagingLabeling/GRAS/Notic eInventory/ucm475293.pdf. Accessed 1 Sept 2021.

170. Liang M, Chen M, Liu X, Zhai Y, Liu XW, Zhang H, Xiao M, Wang P. Bioconversion of D-galactose to D-tagatose: continuous packed bed reaction with an immobilized thermostable L-arabinose isomerase and efficient purification by selective microbial degradation. Appl Microbiol Biotechnol. 2012;93:1469-74. https://doi.org/10.1007/s00253-011-3638-z.

171. Wanarska M, Kur J. A method for the production of D-tagatose using a recombinant Pichia pastoris strain secreting $\beta$-D-galactosidase from Arthrobacter chlorophenolicus and

\section{Authors and Affiliations}

\section{Carlos Vera $^{1}\left[\right.$ Cecilia Guerrero ${ }^{2} \cdot$ Andrés Illanes $^{2}$}

1 Department of Biology, Faculty of Chemistry and Biology, Universidad de Santiago de Chile, (USACH), Santiago, Chile a recombinant L-arabinose isomerase from Arthrobacter sp. 22c. Microb Cell Fact. 2012;11:113. https://doi.org/10.1186/ 1475-2859-11-113.

172. Cervantes FV, Neifar S, Merdzo Z, Vina-Gonzalez J, FernandezArrojo L, Ballesteros AO, Fernandez-Lobato M, Bejar S, Plou FJ. A three-step process for the bioconversion of whey permeate into a glucose D-free tagatose syrup. Catalysts. 2020;10:1-14. https://doi.org/10.3390/catal10060647.

173. Maischberger T, Nguyen TH, Sukyai P, Kittl R, Riva S, Ludwig R, Haltrich D. Production of lactose-freegalacto-oligosaccharide mixtures: comparison of two cellobiose dehydrogenases for the selective oxidation of lactose to lactobionic acid. Carbohydr Res. 2008;343:2140-7. https://doi.org/10.1016/j.carres.2008.01.040.

174. Sheldon RA. Metrics of green chemistry and sustainability: past, present, and future. ACS Sustain Chem Eng. 2018;6:32-48. https://doi.org/10.1021/acssuschemeng.7b03505.

2 School of Biochemical Engineering, Pontificia Universidad Católica de Valparaíso (PUCV), Valparaiso, Chile 